Utah State University

DigitalCommons@USU

$12-2009$

\title{
Selected Barriers and Incentives for Participation in a University Wellness Program
}

Trever J. Ball

Utah State University

Follow this and additional works at: https://digitalcommons.usu.edu/etd

Part of the Public Health Commons

\section{Recommended Citation}

Ball, Trever J., "Selected Barriers and Incentives for Participation in a University Wellness Program" (2009). All Graduate Theses and Dissertations. 515.

https://digitalcommons.usu.edu/etd/515

This Thesis is brought to you for free and open access by the Graduate Studies at DigitalCommons@USU. It has been accepted for inclusion in All Graduate Theses and Dissertations by an authorized administrator of DigitalCommons@USU. For more information, please contact digitalcommons@usu.edu.

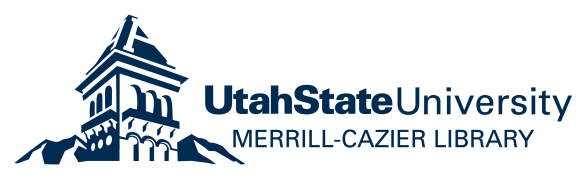




\section{SELECTED BARRIERS AND INCENTIVES FOR PARTICIPATION \\ IN A UNIVERSITY WELLNESS PROGRAM}

by

Trever J. Ball

A thesis submitted in partial fulfillment

of the requirements for the degree

of

MASTER OF SCIENCE

in

Health, Physical Education and Recreation

Approved:

Edward M. Heath, Ph.D.

Phillip J. Waite, Ph.D.

Major Professor

Committee Member

Scott C. Bates, Ph.D.

Byron R. Burnham, Ed.D.

Committee Member

Dean of Graduate Studies

UTAH STATE UNIVERSITY

Logan, Utah 
Copyright (C) Trever J. Ball 2009

All Rights Reserved 


\author{
ABSTRACT \\ Selected Barriers and Incentives for Participation \\ in a University Wellness Program \\ by \\ Trever J. Ball, Master of Science \\ Utah State University, 2009
}

Major Professor: Dr. Edward M. Heath

Department: Health, Physical Education and Recreation

Evidence supporting the benefits of worksite health promotion (WHP) programs is extensive. Research shows these programs can improve the health of participants, lower health care costs, and improve the bottom line of employers. Although the evidence of these benefits is vast, reported participation in WHP is not optimal. Little published data exists on employees' perceived incentives and barriers for participation in WHP.

The purpose of this study was to determine perceived barriers and incentives for participation in an existing WHP program at a large land-grant university. Opinions of eligible WHP participants were collected using a web-based questionnaire $(n=321)$. The questionnaire was adapted from questions used in the 2004 HealthStyles survey. Overall percentages and odds ratios of responses were calculated and stratified by demographics.

Respondents were $68.5 \%$ female, $76.6 \%$ were college graduates, $47 \%$ were 
active, and $32.7 \%$ had a $\mathrm{BMI} \geq 30$. The most common reported barrier to using employee wellness services was no time during work day $(60.2 \%)$. Women were more likely than men to report lack of energy (OR, 4.5; 95\% CI, 1.7-11.9) and no time during work day (OR, 2.6; 95\% CI, 1.4-4.8) as barriers to participation. Respondents who were underweight and overweight were less likely to report lack of energy than respondents who were obese (OR, 0.2; 95\% CI, 0.1-0.6; OR, 0.4; 95\% CI, 0.2-0.9). The most common reported incentive was having programs at a convenient time (66.6\%). Younger respondents were much more likely to report paid time off work to attend as incentive to participate than respondents 60 or more years (18-29 years OR, 10.8; 95\% CI, 2.9-40.1; 30-34 years OR, 4.2; 95\% CI, 1.5-11.7; 35-44 years OR, 3.1; 95\% CI, 1.3-7.4). Most preferred wellness service or policies were available fitness center $(75.9 \%)$, health screening tests $(75.6 \%)$, and paid time to exercise at work $(69.6 \%)$. The results of this study, combined with an employer's own employee needs assessment, may help universities, and other employers with similar characteristics, design more attractive employee wellness programs. Making employee wellness programs attractive to their potential participants may improve program participation. 


\section{CONTENTS}

Page

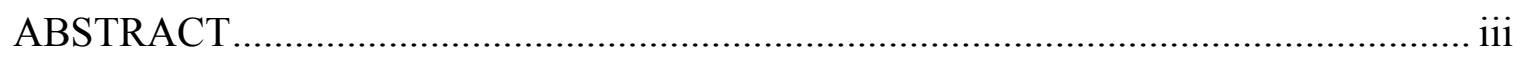

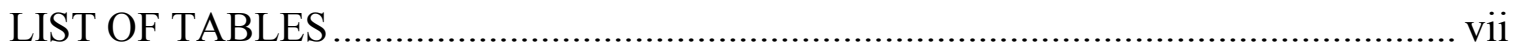

\section{CHAPTER}

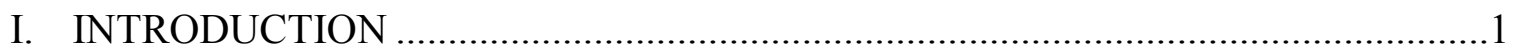

Purpose of the Study......................................................................................

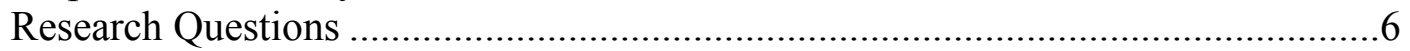

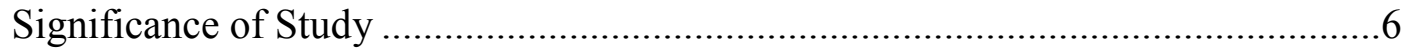

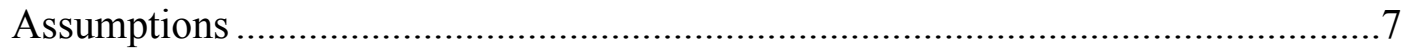

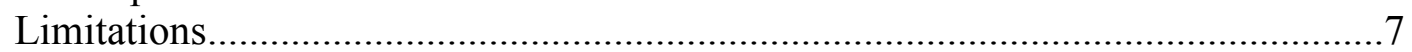

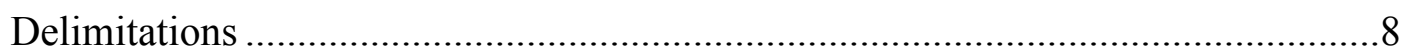

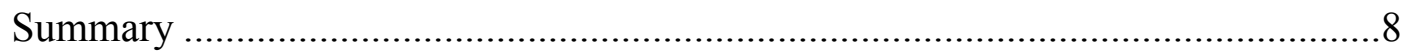

II. REVIEW OF LITERATURE ......................................................................

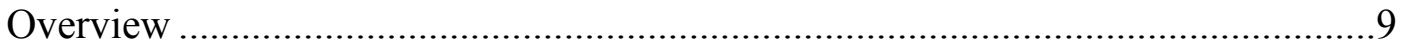

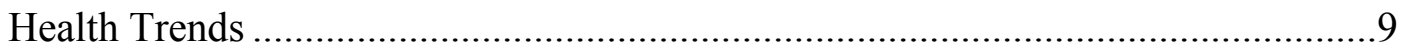

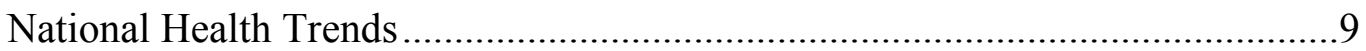

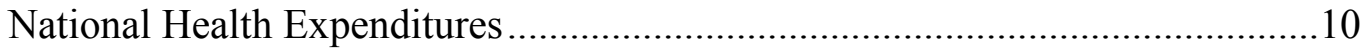

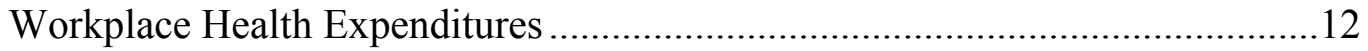

Worksite Health Promotion ................................................................................ 17

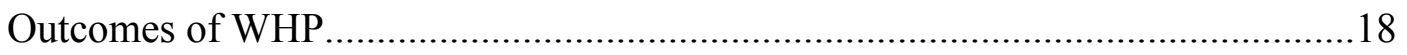

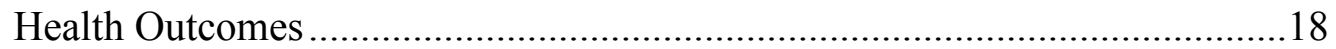

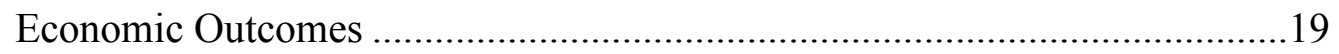

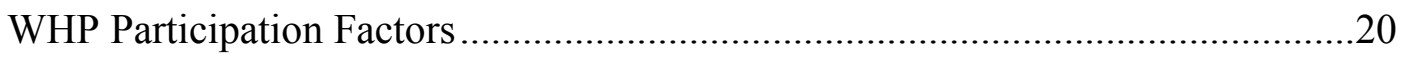

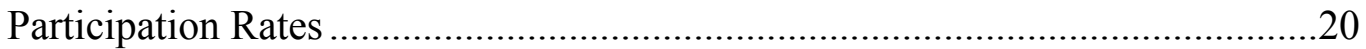

Theoretical Perspectives ..........................................................................26

Transtheoretical Model ...............................................................................26

Barriers and Incentives in Higher Education WHP.........................................29

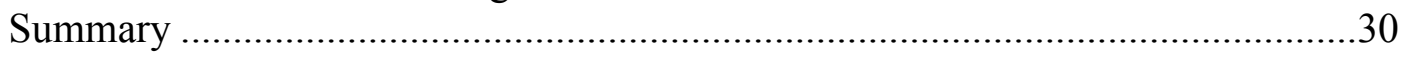




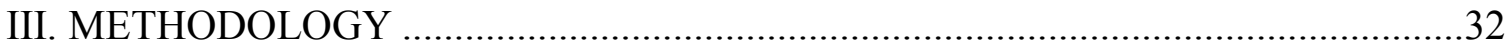

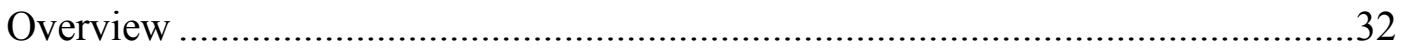

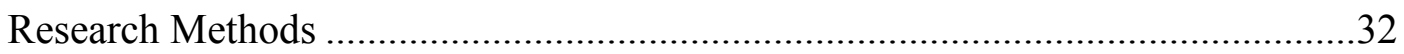

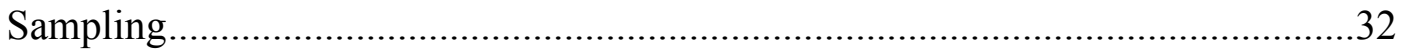

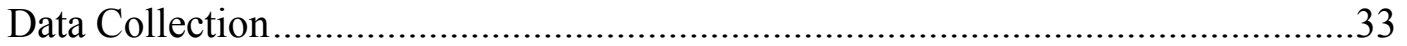

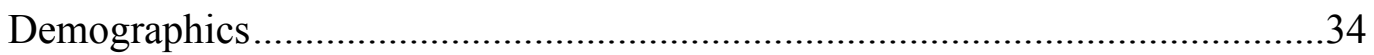

Perceived Use of Employee Health Promotion Services and Policies ..................35

Participation in Physical Activity Services...................................................35

Participation in Nutrition Awareness Services ...............................................35

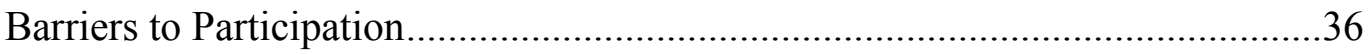

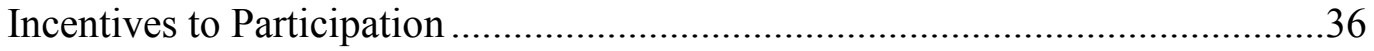

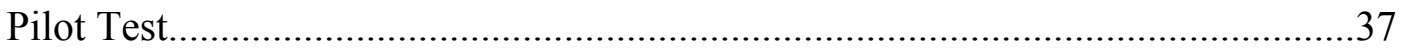

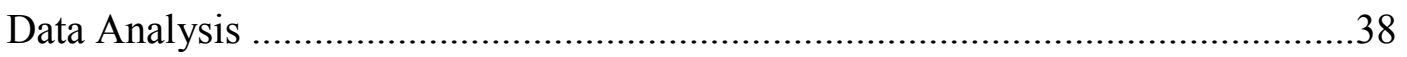

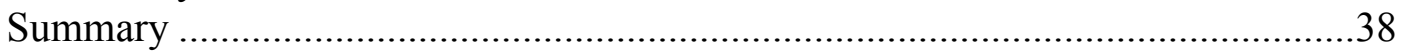

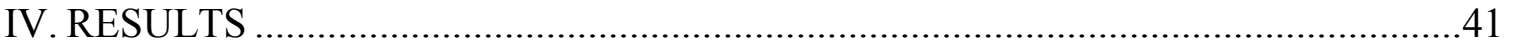

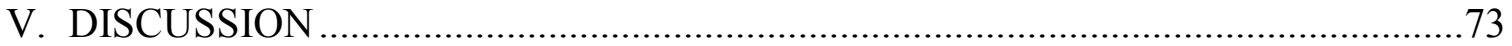

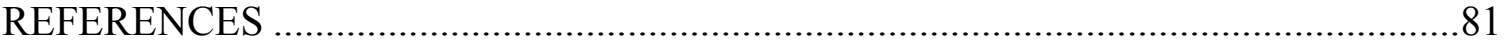

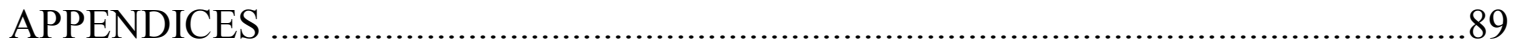

Appendix A. Informed Consent Form ......................................................... 90

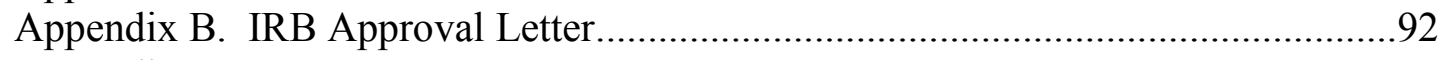

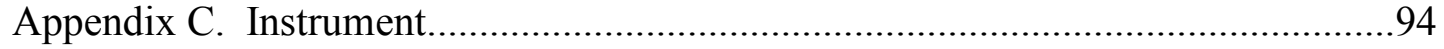




\section{LIST OF TABLES}

Table

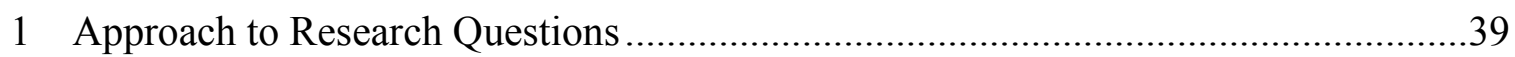

2 Demographics Used to Weight Sample Data............................................................ 40

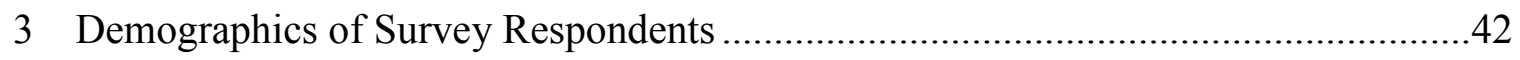

4 Perceived Use of Physical Activity Services Among Benefits-Eligible Employees.

5 Perceived Use of Nutrition Awareness Services Among Benefits-Eligible

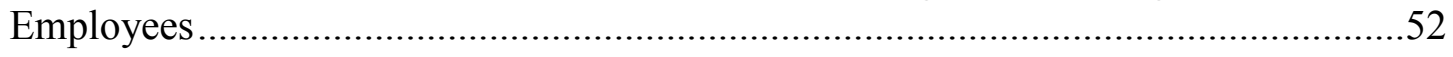

6 Selected Barriers to Wellness Services Among Benefits-Eligible Employees............58

7 Selected Incentives to Wellness Services Among Benefits-Eligible Employees ........67 


\section{CHAPTER I}

\section{INTRODUCTION}

Substantial increases in United States (U.S.) health care costs over the past two decades are attributed in large part to an aging population, and a substantial increase in preventable diseases (Arias, 2007; McGinnis \& Foege, 1993; National Center for Health Statistics [NCHS], 2009). Of a more expedient concern are the preventive illnesses. In 2000 , tobacco use was the leading cause of death, closely followed by poor diet and physical inactivity, and then alcohol consumption (Mokdad, Marks, Stroup, \& Gerberding, 2004). Current health research and literature provide extensive evidence for the urgency of the U.S. health care and public health systems to become more prevention oriented (Flegal, Carroll, Ogden, \& Johnson, 2002; Ogden et al., 2006).

Beyond the negative consequences of poor health on individuals, businesses in America are also suffering sizeable financial consequences resulting from the poor health of their employees. Goetzel, Hawkins, Ozminkowski, and Wang (2003) assessed financial costs attributed uniquely to the physical health problems of the employees of six large U.S. employers. In their analysis, physical health problems were found to cost over $\$ 3,500$ per employee per year.

Because obesity generally results in more extensive risk factors than other physical conditions, costs of obesity in the workplace have garnered considerable attention when assessing health costs of businesses. Obesity exclusively relates to a myriad of risk factors and chronic conditions. Some of these risk factors include various types of cancer, hypertension, hyperlipidemia, insulin resistance, glucose intolerance, 
type 2 diabetes mellitus, coronary artery disease, and stroke (Pi-Sunyer, 1993). In a recent estimate, obesity-related absenteeism was shown to cost a company of 1000 employees approximately $\$ 285,000$ per year (Finkelstein, Fiebelkorn, \& Wang, 2005). Not included in the estimate of Finkelstein et al. are presenteeism (i.e., reduced on-thejob productivity) and disability costs that experts believe to be extensively associated with obesity.

Health promotion programs at the worksite have emerged as a core strategy to improve individual health as well as the success of businesses (Chapman, 2005; Harden, Peersman, Oliver, Mauthner, \& Oakley, 1999; Ogden et al., 2006; Shain \& Kramer, 2004). The American College of Sports Medicine describes worksite health promotion (WHP) as multidisciplinary field that seeks to improve health through a variety of theories and interventions (Cox, 2003).

The majority of Americans spend a substantial amount of their time at the workplace, and the workplace has consequently become a more common place to promote health. In 2006 , more than $60 \%$ of the U.S. population aged at-least 16 years or older were employed by public or private employers (United States Census Bureau, 2006). WHP has also become an important objective in the United States Department of Health and Human Services (DHHS) Healthy People initiatives. Healthy People 2010 specifically encourages that the number of worksites with 50 or more employees offering nutrition and weight management services at work increase from 55-85\% (Department of Health and Human Services [DHHS], 2000). 
Successful WHP programs have demonstrated not only to considerably improve the health of employees (Goetzel \& Ozminkowski, 2008), but also the financial bottom line of their employers (Chapman, 2005; DHHS, 2003). In a review of literature of the financial impact of WHP programs, Aldana (2001) concluded that there is consistent evidence of a correlation between high levels of stress, excessive body weight, and multiple risk factors and increased health care costs and illness-related absenteeism. After reviewing 56 WHP economic return studies, Chapman (2005) discovered the average reduction (result of WHP interventions) in sick leave, health plan costs, and workers' compensation was more than $25 \%$. Furthermore, return on investment (ROI) studies have consistently shown a \$3-8 ROI per dollar spent towards WHP programs within 5 years of program initiation (Aldana).

Notwithstanding the mounting evidence supporting the benefits of WHP programs, there is a widening gap between publication and intervention (Glasgow, Lichtenstein, \& Marcus, 2003; Kerner, Rimer, \& Emmons, 2005; Lahtinen, KoskinenOllonqvist, Rouvinen-Wilenius, Tuominen, \& Mittelmark, 2005). One of the more concerning determinants of program success is the few and low reported participation rates of WHP programs (Glasgow, McCaul, \& Fisher, 1993; Kwak, Kremers, van Baak, \& Brug, 2006).

Reported WHP participation has generally been low (Busbin \& Campbell, 1990; Crump, Earp, Kozma, \& Hertz-Picciotto, 1996; Crump, Shegog, Gottlieb, \& Grunbaum, 2001; Resnicow et al., 1998; Shephard, 1996). Program participation concerns addressed even less than the reporting of rates are strategies to increase the participation. Some of 
these overdue strategies include: assessing eligible participants to determine their perceived barriers and incentives to participation, determining and manipulating the variables that predict participation, standardizing definitions of participation, researching more of the worksite level variables, collecting general needs and assessment data, and incorporating more behavioral and organizational theory (Glasgow et al., 1993; Kruger, Yore, Bauer, \& Kohl, 2007; Serxner, Anderson, \& Gold, 2004a).

It is noteworthy that the majority of WHP evaluations involve businesses and industry. Ironically, evaluating WHP programs is less common within government and higher education settings, where environments and resources cater to the research and development of programs. Just as health promotion has proven to be a benefit in the corporate and small business settings, it is deemed important for universities as well (Barker \& Glass, 1990; Belcher, 1990; Bruce, 1993; Bull, Eckerson, Moore, Pfeifer, \& Obermiller, 2006; Haines et al., 2007; Reger, Williams, Kolar, Smith, \& Douglas, 2002; Williams, 1988). Between 2004 and 2005 more than 3.3 million people were employed at postsecondary U.S. institutions (Knapp et al., 2006), making the higher education work environment an important potential avenue for promoting health through WHP programs.

An important requirement of success for WHP programs is the evaluation of employee perceived barriers and incentives for participating in the programs. Effective WHP depends on the employers' and employees' willingness to participate. It is also important; therefore, to collect their opinions in order to make programs relevant and acceptable (Chenoweth, 1999; Cox, 2003; Glasgow et al., 1993; Serxner et al., 2004a). Leading worksite health promotion investigators suggest that by targeting setting-specific 
barriers it is also possible to compare findings across work settings with similar characteristics (Kruger et al., 2007). A considerable number of people and higher education worksites could benefit from the evaluation of employee barriers and incentives to participation in WHP programs.

\section{Purpose of the Study}

Evidence supporting the benefits of WHP programs is extensive and continues to grow today. Research shows that these programs can improve the health of their participants, lower health care costs, and improve the bottom line of employers. Although the evidence of these benefits is vast, reported participation rates in WHP programs are far from what many feel would yield considerably greater benefits. To date, there is little published data regarding employees' perceived incentives and perceived barriers for participation in these programs. The purpose of this study was to determine the perceived barriers and incentives for participation in an existing comprehensive employee wellness program at Weber State University.

There may be other higher education institutions that have evaluated similar employee health promotion program needs. Other universities and colleges should compare the results of this study to their own, similar studies. Data reported in this study, combined with other institutions' own internal assessments may help those organizations better design health promotion programs to meet the needs of their employees, manage the appropriate incentives for participation, and increase and enhance participation. 
Research Questions

This study will address the following questions:

1. What are the employee perceived barriers and incentives to participation in their employee wellness program?

2. What is the relationship between demographics and the perceived barriers and incentives to participation?

3. What is the relationship between the perceived barriers and incentives of current employee wellness participants, and the perceived barriers and incentives of nonparticipants?

\section{Significance of Study}

1. Guidelines in Healthy People 2000 endorse the need for WHP programs. The DHHS specifically identifies universities and colleges as key locations for workplace health promotion programs (DHHS, 2000).

2. To add to the results of other studies done with college and university health promotion. By further examining the determined barriers to and incentives for participation of other university health promotion studies, along with those of this study we can establish a better knowledge of barriers and incentives for the higher education employment setting. Worksite settings with similar characteristics could also apply the results of this study.

3. Higher education worksites are excellent environments for researching and developing WHP programs. 
4. Considerably more WHP research is performed within business and industry than it is within higher education institutions, despite the favorable research conditions of higher education institutions.

5. WHP is important for the health and bottom line of universities.

\section{Assumptions}

The assumptions of this study included the following:

1. Anonymous questionnaires are valid instruments to measure demographic characteristics, perceived barriers and incentives to participation, and perceived health interests.

2. Respondents of questionnaires did so honestly and to the best of their ability.

\section{Limitations}

The limitations of this study included the following:

1. Research utilizing a questionnaire has inherent limitations, including the willing cooperation of the participants, their honesty of reporting, accuracy of the questionnaire's administration, and the use of a sample of convenience. The employees who chose to participate in this study may have been different from those who chose not to participate in the study.

2. This study applied only to the respondents of the questionnaire, thus generalizations of the findings should be approached cautiously. 


\section{Delimitations}

The delimitations of this study included the following:

1. The study population was limited to a survey of employees of only one university.

2. The categories of variables were limited to demographics only.

3. The questionnaire was administered in summer 2009 .

4. The instrument utilized for this study was only one questionnaire, and administered only via email and the internet.

Summary

This chapter provided a short background on the prevalence of common health problems that face the people of the United States, and its businesses. It also reviewed the economic and efficacy impacts of health problems within the common workplace. The history and scope of worksite health promotion programs were introduced, as well as current trends in the evaluation of their effectiveness. Strategies to increase participation rates in worksite health promotion programs were presented, including the purpose of this study - measuring perceived barriers and incentives for participation. This chapter also discussed the research questions, significance, assumptions, limitations, and delimitations of this study. 
CHAPTER II

REVIEW OF LITERATURE

\section{Overview}

The previous chapter discussed briefly the prevalence and benefits of WHP programs, trends in participation rates, and the significance of WHP in the higher education setting. Details of this study including its purpose, significance, assumptions, limitations, delimitations, and research questions were also presented.

This chapter will review in more detail the literature pertinent to the topics introduced in Chapter I. Specifically, this chapter will review current health trends in the U.S., national and workplace health expenditures, a history of workplace health promotion, and the health and economic outcomes of WHP. This chapter will conclude with a review of trends in WHP participation rates, and the prevalence of WHP within the higher education setting.

\section{Health Trends}

\section{National Health Trends}

It is noteworthy that although life expectancy in the United States has consistently increased over the past few decades, the leading causes of death continue to be the results of adverse life styles such as tobacco use, poor diet and physical activity, and alcohol consumption (Arias, 2007; Mokdad et al., 2004; NCHS, 2009). The Centers for Disease Control and Prevention indicate that about one-half of all deaths of persons under the age of 65 years are attributable to unhealthy life styles (Mokdad et al.). 
The prevalence of people in the U.S. with unhealthy lifestyles, such as lack of physical activity and overweight, has most noticeably increased in the past three decades. When a representative sample of the United States was surveyed by phone between years 2000-2001, it was learned that the majority of persons in the United States did not engage in enough physical activity consistent with the then used recommendation of 30 minutes of moderate-intensity activity most days of the week. In $2001,54.6 \%$ of persons were determined not active enough to meet these recommendations (Macera et al., 2003).

According to Ogden et al. (2006), the percentages of adults that are overweight or obese have risen from $47 \%$ in $1976-1980$ to $66.3 \%$ in $2003-2004$. The exclusive prevalence of obesity in adults has increased noticeably from $15 \%$ in $1976-1980$ to $32.2 \%$ in 2003-2004. Excessive amount of body weight is associated with excess morbidity and mortality (Donato, 1998). The risks of heart disease, diabetes, and some types of cancer are also linked to overweight and obesity. The severity of hypertension, arthritis, and other musculoskeletal problems are increased as well with overweight and obesity (DHHS, 2000; Pi-Sunyer, 1993). There is ample evidence supporting the urgency of the U.S. health care and public health systems to become more preventive oriented (McGinnis \& Foege, 1993; Mokdad et al., 2004; NCHS, 2009)

\section{National Health Expenditures}

Perhaps of equal growing concern as the consequences of poor health in individuals are the economic burdens created by these increases of preventive illnesses. The U.S. spends more on health per capita than any other country, and the health spending in the U.S. continues to increase. Important factors contributing to our health 
cost increases include greater intensity and cost of services, a significant increase of treatments for our aging population, and increases in preventable diseases (Finkelstein et al., 2005). In 2006, U.S. health care spending amassed $\$ 2.1$ trillion - approximately $16 \%$ of our gross domestic product. The United States spends a greater portion of its gross domestic product on health than does any other industrialized country (Poisal et al., 2007).

While our country's total health care expenses continue to rise, the prevalence of illnesses related to modifiable risk factors and poor lifestyle habits is also rising. This is especially alarming because those suffering these illnesses generate significantly higher health care costs (Goetzel \& Stewart, 2000). Because levels of physical inactivity and excess weight have risen to epidemic levels in the U.S., some researchers have conducted analyses of the financial costs burden of physical inactivity and excess weight.

Chenoweth and Leutzinger (2006) used a variety of data in order to quantify the costs of physical inactivity and excess weight among American adults. Data were used from seven different states that the authors felt characteristically represented the U.S. Medical and workers' compensation cost data on selected medical conditions, as well as productivity loss norms were obtained from each of the seven states.

The overall financial burden of the seven states, which included direct medical care costs, workers' compensation, and productivity loss, amassed $\$ 93.32$ billion for physical inactivity and $\$ 94.33$ billion for excess weight. These calculations were then used to estimate a $\$ 507$ billion cost to the nation for only these two health risk factors. These, and other authors, note that a substantial loss in productivity as a result of physical 
inactivity and obesity may likely be our greatest financial concern, as opposed to the direct medical care costs of these risks (Burton et al., 2005; Goetzel et al., 2004; Pelletier, Boles, \& Lynch, 2004)

National health care expenditures per capita rose 77\% between 1995 and 2005. National health expenditures for treatments related to substance abuse increased by nearly 50\% (inflation-adjusted) from 1986 to 2003. The total health expenditure for substance abuse treatment was more than $\$ 20$ billion in 2003 (NCHS, 2008).

\section{Workplace Health Expenditures}

According to Koretz (2002), employers pay more than one third of the U.S.'s total annual medical expenditures. The remaining balance is paid by Medicare, Medicaid, other government programs, individual insurance coverage, and patient out-of-pocket expenditure. In 2006, employer premiums for medical care reportedly averaged \$3615 a year for single coverage and $\$ 8508$ for family coverage (Kaiser Family Foundation, 2008). As total health expenditures in the U.S. continue to increase, health related expenses of businesses are also increasing. Businesses are thus urgently assessing their own avenues for reducing health related expenses.

Goetzel et al. (1998) and Anderson et al. (2000) examined the relationship between 10 modifiable health risk factors and medical claims for more than 46,000 employees from private and public employers over a 6-year period. The risk factors examined were obesity, high serum cholesterol, high blood pressure, stress, depression, smoking, diet, excessive alcohol consumption, physical fitness and exercise, and high blood glucose. It was discovered that these 10 risk factors accounted for roughly $25 \%$ of 
the employers total health care expenditures for the employees included in the studies. Furthermore, the employees with the risk factors of tobacco use, high blood pressure, high cholesterol, overweight/obesity, high blood glucose, high stress, and lack of physical activity accrued $228 \%$ more in health care costs than the employees lacking these risk factors.

The cost burden of health conditions within a business were first assessed by examining inpatient and outpatient insurance claims (Flegal et al., 2002). However, more recently it has been suggested that the direct medical costs of employees account for less than half of the total health and productivity-related expenditures that employers have. Goetzel, Guindon, Turshen, and Ozminkowski (2001) have suggested that more than half of employer's health and productivity-related expenses exist in more indirect ways such as absenteeism from work, use of disability benefits, worker compensation benefits, employee turnover, family medical leave, and less productivity at work. Although these costs are not direct medical costs they are most often a result of related medical conditions.

Greenberg, Finkelstein, and Berndt (1995) also suggested that the direct medical costs are only a small portion of the total costs associated with health and disease conditions of employees. Greenberg and his colleagues asserted that it is common for businesses to overlook the indirect costs of employee health issues. To explain further the implications a narrow focus on direct health expenses can have, they reviewed the economic expenditures of employees diagnosed with depression. It was noted that depression is the most common clinical problem in primary care. As a result of their 
review, Greenberg et al. reported that almost three-quarters of the costs of depression are indirect costs, such as a lost of earnings due to reduced productivity and depressionrelated suicides.

Using a database of six large employers that linked medical care and employee productivity Goetzel et al. (2003) identified 10 most costly physical and mental health conditions. Similar to the findings of Greenberg and colleagues (1995), Goetzel and colleagues found that significant portions of their subject's health expenditures came from indirect costs. Twenty-nine percent of the total health expenditures for physical health conditions were constituted by absence and disability costs (productivity). When mental health conditions were examined, they found that absence and disability costs constituted $47 \%$ of total mental health expenditures.

The 10 most costly physical health conditions found were (a) angina pectoris; (b) essential hypertension; (c) diabetes mellitus; (d) mechanical low back pain; (e) acute myocardial infarction; (f) chronic obstructive pulmonary disease; (g) back disorders not specified as low back; (h) trauma to spine and spinal cord; (i) sinusitis; and (j) diseases of the ear, nose and throat or mastoid process. The most costly mental health disorders were (a) bipolar disorder; (b) chronic maintenance; (c) depression; (d) depressive episode in bipolar disease; (e) neurotic, personality and non-psychotic disorders; (f) alcoholism; (g) anxiety disorders; (h) schizophrenia; (i) acute phase; (j) bipolar disorders; (k) severe mania; (l) nonspecific neurotic; (m) personality and non-psychotic disorders; and (n) psychoses. 
Also discovered in their study was that the employers paid a mean of $\$ 3524$ per employee for physical conditions related to health and productivity. Seventy-one percent of this amount was attributed to medical care, $20 \%$ for absenteeism, and $9 \%$ was attributed to short-term disability.

In a later study, Goetzel et al. (2004) assessed the costs of specific physical and mental health conditions. In this review, Goetzel et al. identified several studies that attempted to quantify the costs of on-the-job productivity, as influenced by various health conditions. In their review, they found the most common health conditions that affect employers financially were cardiovascular disease, musculoskeletal disorders, ear, nose and throat conditions, hypertension, diabetes, and depression-related illnesses.

Perhaps of greatest economic health concern to employers are obesity-attributable health expenditures. Thompson, Edelsberg, Kinsey, and Oster (1998) estimated the costs of obesity to U.S. businesses using data from the U.S. Bureau of Labor Statistics (BLS). They first estimated total annual expenditures for health, life, and disability insurance and paid sick leave by private-sector firms in the U.S. in 1994. They then estimated the proportions of the expenditure totals that were attributable to obesity. Lastly, BMI values were calculated using height and weight data from the same BLS reports. Persons were classified as either "nonobese" (BMI < 25), "mildly obese" (BMI = 25-28.9), or "moderately to severely obese" (BMI $\geq 29)$.

In their study, Thompson et al. (1998) estimated that obesity cost U.S. businesses $\$ 12.7$ billion in 1994 , with $\$ 2.6$ billion attributed to mild obesity, and $\$ 10.1$ billion attributed to moderate-to-severe obesity. In addition, health insurance costs accounted 
for more than half of the total obesity-attributable expenditures. Paid sick leave was the next most common expenditure related to obesity, followed by life insurance, and disability insurance.

Sturm (2002) estimated that, on average, obese adults (BMI $\geq 30)$ incur $36 \%$ more annual medical costs than normal-weight adults. Finkelstein, Fiebelkorn, and Wang (2003) further estimated that overweight and obesity account for $9.1 \%$ of total annual U.S. medical expenditures.

Another significant indirect cost found as a result of overweight and obesity is missed workdays. For example, Thompson et al. (1998) compared mean missed workdays for overweight and obese employees $(\mathrm{BMI}>29)$ with mean missed days of normal-weight employees $(\mathrm{BMI}<25)$. Their results showed that obese male employees missed up to 2.7 more days per year than normal-weight males, and obese females missed up to 5.1 more days than normal-weight females. Thompson noted that although a portion of the obesity-related costs is accrued by the employees, employers will still be burdened with their own obesity-related costs, such as less productivity as a result of more missed workdays.

Finkelstein, Ruhm, and Kosa (2005) attempted to estimate the dollar value of overweight and obesity-attributable missed workdays. In their analysis they found that the per capita increase in medical expenditures and absenteeism associated with overweight and obesity ranged from $\$ 176$ per year for overweight male employees to $\$ 2485$ for grade-II $\left(\mathrm{BMI} \geq 35 \mathrm{~kg} / \mathrm{m}^{2}\right)$ obese female employees. Of even greater concern than these costs is that the prevalence of obesity is increasing, as well as the proportion of 
those that are obese with grades- II and -III (BMI $\geq 40 \mathrm{~kg} / \mathrm{m}^{2}$ ) obesity (Chapman, 2005; DHHS, 2003; Harden et al., 1999; Shain \& Kramer, 2004). Finkelstein and colleagues (2005) noted that the costs of obesity only employees (not overweight employees) can cost a firm of 1000 employees approximately $\$ 285,000$ per year. They also estimated that approximately $30 \%$ of this cost is from absenteeism. This study did not consider other potential costs associated with obesity, such as presenteeism and disability, and therefore could be a conservative estimate of the costs of obesity to employers.

\section{Worksite Health Promotion}

One strategy to improve individual health as well as the success of businesses is health promotion programs at the worksite. In 2006 , more than $60 \%$ of the U.S. population aged at-least 16 years or older were employed by public or private employers (Harden et al., 1999). Because the workplace is where the majority of Americans spend a substantial amount of their time, it has become a common place to promote health. WHP has also become an important objective in the U.S. DHHS Healthy People initiatives. Specifically, Healthy People 2010 encourages that the number of worksites with 50 or more employees offering nutrition and weight management services at work increase from $55-85 \%$ (DHHS, 2000).

The American College of Sports Medicine describes WHP as ...a comprehensive, multidisciplinary, and complex field that seeks to promote, improve, and optimize health, well-being, and performance of those associated with a place of employment. It draws, as a discipline, on a variety of specialized areas such as behavioral and social science, econometrics, organizational learning, business administration, epidemiology, preventive medicine, and political science, to name a few. In all, it brings together the most meaningful set of theories, 
principles, approaches, and ideas that, as a whole, facilitate the improvement of health. (Cox, 2003, p. 4)

\section{Outcomes of WHP}

\section{Health Outcomes}

Successful WHP programs have shown to benefit the health of employees as well as the financial bottom line of businesses. In 2007, the Community Guide Task Force (division of the U.S. Center for Disease Control \& Prevention) published a comprehensive review of literature focused on the health and economic impacts of WHP (Goetzel \& Ozminkowski, 2008). The Task Force included in their review literature for WHP programs that utilized some form of assessment of health risks, followed by interventions targeted at improving the health status of participants. Fifty studies were consequently included in the Task Force's review. Health and productivity outcomes of the evaluated studies ranged from health behaviors, productivity indicators linked to health status, and physiological markers of health. The Task Force found several positive changes in these outcomes, although they were small at the individual level. The population level, however, displayed much more significant changes.

Evidence for improved health behaviors and outcomes attributed to WHP was specifically found with the following: (a) reduction of tobacco use among participants, (b) less self-reported dietary fat consumption, (c) reduction in blood pressure and cholesterol levels, and (d) fewer missed work days due to disability or illness, as well as improvements in other indicators of productivity. Evidence was considered insufficient, however, for program outcomes such as increased consumption of fruits and vegetables, 
reduced overweight and obesity, and improved physical fitness. The Task Force also did not find sufficient evidence to determine the effectiveness of Health Risk Assessments (HRA) with feedback when no follow-up was implemented.

\section{Economic Outcomes}

Successful WHP programs have been shown not only to appreciably improve the health of employees, but also the financial bottom line of their employers. In a review of literature of the financial impact of health promotion programs, Aldana (2001) concluded that there is consistent evidence of a relationship between high levels of stress, excessive body weight, and multiple risk factors and increased health care costs and illness-related absenteeism. Measuring variables that affect absenteeism has become critical in WHP financial outcomes research because a significant amount of employer health costs are a result of absenteeism.

Of the 56 WHP economic return studies evaluated by Chapman (2005), the average reduction (as result of WHP) in sick leave, health plan costs, and workers' compensation was more than $25 \%$. It is noteworthy; however, that Chapman also determined that research investigating the economic impacts of WHP programs is lacking a standardization of methodology used in the economic analysis. Regardless of the methodological deficiencies, Chapman also noted that the results of WHP economic studies are consistently showing a high amount of congruence. One thing ROI studies have consistently shown is a \$3 - 8 ROI per dollar spent towards WHP programs within 5 years of program initiation (Serxner et al., 2004a). 


\section{WHP Participation Factors}

\section{Participation Rates}

One of the primary rationales for implementing health promotion programs and activities at the worksite is the potential to reach a high percentage of people. There is also potential to modify the health of individuals who otherwise would be unlikely to participate in preventive health behaviors. Because WHP programs are only successful to the extent that both employers and employees participate, programs are constantly exploring interventions to increase and enhance participation (Glasgow et al., 1993).

Although there is mounting literature on WHP, few programs report data that concern participation. Assessing and increasing participation rates are important for both research and practice. Assessing and increasing WHP participation is most important because it has an impact on program justification, effective delivery and evaluation, and increases the generalizability of findings (Glasgow et al., 1993; Linnan, Sorensen, Colditz, Klar, \& Emmons, 2001)

In a review of WHP participation literature, Lovato and Green (1990) learned that most WHP programs do not report participation data. They also noted that when participation data are reported, definitions and rates of participation vary greatly. A reoccurring challenge in studies that do report WHP participation rates is operationally defining participation. Defining participation has varied greatly from both the employee and worksite level (Serxner, Anderson, \& Gold, 2004b). For example, one worksite could consider attendance to at-least $50 \%$ of their health promotion services participation, while another worksite might consider participation as attendance to at least one health 
promotion service in a given year. Glasgow et al. (1993) noted that different predictors are likely to be related to the various definitions of participation, and thus the participation rates recorded from the measures cannot be compared. When participation rates are recorded, Glasgow and colleagues suggested a need to include in publication how the rates are determined.

Goetzel, Ozminkowski, et al. (2001) surveyed organizations recognized by the American Journal of Health Promotion as having demonstrated an improvement in population health and reducing costs resulting from their health promotion interventions. The intent of surveying the award-winning WHP organizations was to better understand factors that have enhanced or impeded the growth of the health promotion programs of the organizations. The average employee participation rate among the top organizations recognized was $60 \%$.

Glasgow et al. (1993) were led to believe that the costs of health risks were high compared to the costs of risk reduction programs, and as a result WHP programs could achieve a positive ROI from even low rates of participation. In their article focusing on ways to increase and improve participation, they suggest that even minor improvements in participation rates could considerably improve the ROI of the program.

Glasgow et al. (1993) concluded from their study that knowledge of determinants of participation needs to be studied more and that it could be accelerated by standardizing definitions of participation. They recommended that investigations of determinants of participation should be driven by behavioral and organizational theory and to perform assessments that integrate the results of those investigations. Glasgow and colleagues 
believe we need to discover the variables that predict participation first, and then experiment with interventions that attempt to increase participation through manipulation of those variables.

Lerman and Shemer (1996) and Lewis, Huebner, andYarborough (1996) reviewed studies that did collect participation data and concluded that one-quarter to one-half of employees offered health promotion services participated in those services. Another concern with collecting WHP participation data is that many of those reported as participating might only be the healthiest employees (Lassen et al., 2007).

Effective WHP depends on the employers' and employees' willingness to participate. Therefore, it is also important to collect their opinions in order to make programs relevant and acceptable (Chenoweth, 1999; Cox, 2003; Glasgow et al., 1993; Serxner et al., 2004a). Hunt, Lederman, Potter, Stoddard, and Sorensen (2000) found in their evaluation of the TreatWell 5-a-day worksite health program that employee involvement in the creation and implementation of program interventions was correlated with participation in those interventions.

One of the more successful methods of increasing participation in WHP programs at the employee level has been tailoring program interventions to the expressed needs and interests of the eligible participants. This is generally accomplished by administering a needs and interest survey (Harden et al., 1999). The majority of WHP programs are reportedly neglecting to consider the needs and views of their target populations (Hollander \& Lengermann, 1988; Lassen et al., 2007; Serxner et al., 2004a; Shain \& Kramer, 2004). After reviewing 110 WHP outcome evaluations, Harden et al. found that 
only one-quarter of them reported that interventions were implemented in response to views or needs expressed by employees. Although implementing interventions based on the views and opinions of employees does not guarantee their participation in programs or policies participation and general success of WHP programs has shown to be considerably greater when interventions are based on employee input (Brown, 2005; Jaffee, Lutter, Rex, Hawkes, \& Bucaccio, 1999).

In 2004, the National Institute of Occupational Safety and Health held a symposium aimed at improving the health of the United States workforce. A noteworthy outcome of the symposium was discovering the need for more and better WHP development research. Specifically, acceptability of interventions in a specific population, and assessment of potential participation in interventions were addressed as being critical gaps in current WHP research (Sorensen \& Barbeau, 2004).

Perceived barriers to engaging in physical activity are being reported; however, perceived barriers to participating in WHP have received less attention (Crump et al., 1996; Davis, Jackson, Kronenfeld, \& Blair, 1984; Lovato \& Green, 1990; Sloan \& Gruman, 1988). Kruger et al. (2007) recently addressed this gap in WHP development research by evaluating the perceived barriers and incentives to WHP participation of the HealthStyles 2004 consumer survey respondents. As a result of their evaluation, several variables that may predict or improve WHP participation were determined. Kruger and colleagues noted that it is important to identify the perceived barriers and incentives to participation in WHP services and policies in order to implement services and policies that are more attractive to the eligible participants. 
The primary objective of Kruger and others' (2007) study was to discover perceived barriers and incentives of employees to WHP services in hopes that employers would combine the findings of this study with the findings of their own program assessments in order to implement more attractive program features. They also evaluated response differences by demographic characteristics so that results could be utilized in settings with similar characteristics.

The leading responses for perceived use of WHP services supported (said they would use) fitness centers (80.6\%), followed by on-site fitness classes $(55.2 \%)$ and sports leagues $(36.3 \%)$. Women were discovered as being more likely than men to use fitness centers and on-site fitness classes. Both genders were equally represented in the survey (47.9\% men and $52.1 \%$ women).

Leading responses of perceived use of nutrition awareness services were weightloss programs (67.1\%), followed by personalized diet and exercise counseling $(49.8 \%)$, health eating and cooking classes (48.2\%), weight loss support groups, and online tracking tools. Women were much more likely to report that they would use weight loss programs, weight loss support groups, personalized diet and exercise counseling, and health eating and cooking classes.

Most commonly reported barriers to participation in WHP services were no time during work (42.5\%), and lack of time before or after work (39.4). Younger respondents were more likely to report that being too tired was a barrier to WHP participation. Physically active adults were more likely to report that they were already involved with 
other programs (reported as a barrier to participating in services of their employer's WHP program).

Incentives for participating in WHP services were most commonly reported as convenient time (73.2\%), convenient location $(72.8 \%)$, and paid time off from work to participate $(69.6 \%)$. Both women and physically active respondents were more likely to report convenient time and location as incentives to WHP participation. Other demographic characteristics (besides gender) such as age, BMI, ethnicity, and physical activity status were also evaluated amongst responses, however omitted in this review.

Because this study assessed only what eligible WHP participants said they were likely to use if the included services were offered at their worksites as benefits more research needs to be done in determining if they actually do use the services once they are implemented. This study was also valuable in that responses were reported by demographic characteristics. Although there is a significant amount of research supporting the benefits of a variety of WHP programs and services, employers should balance the services according to the demographics of their employees.

Kruger and colleagues suggested that because paid time off work to participate in WHP services was such a highly responded incentive more research will be needed to determine the cost-effectiveness of that specific service. As many others are summoning, Kruger and colleagues encouraged that individual worksites collect their own worksitespecific data. A noteworthy implication of Kruger and others' findings is that in order to design WHP programs that best support behavior change programs should be designed 
not only in terms of identified risk factors and medical costs, but also in consideration of employee preferences.

\section{Theoretical Perspectives}

Theory-driven research in health promotion is commonly used to investigate determinants of a variety of health behaviors, including participation in WHP services. Most theories used to investigate health promotion strategies are stage-based theories, which propose that behavior change is something that happens through a series of different qualitative stages. These types of theories also propose that the barriers people face when trying to change their behavior change at different stages in the process. Consequently, stage-based behavioral theories used in health promotion suggest that interventions are most effective when they are modified to an individual's current stage of change. Although many investigators of WHP research are encouraging a greater use of more theory-driven health promotion research, theory-driven research has only been used in a few approaches in understanding the determinants of low participation in WHP (Prochaska \& Velicer, 1997).

\section{Transtheoretical Model}

When setting participation goals, many worksites will set a goal of maximizing participation in their WHP program. Because not all participation is of equal value with regards to health behavior change and financial return organizations are encouraged to focus on reducing the most costly risks in the population. Reducing the most costly risks in a population involves reaching the right individuals with the right interventions and at a time when they are ready to modify their health behaviors. It is under this basis that the 
Transtheoretical, or stages of change, health behavior model is often applied when implementing health promotion interventions.

The Transtheoretical model suggests that health behavior change involves a progression through six stages of change: precontemplation, contemplation, preparation, action, maintenance, and termination (Linnan et al., 2001; Lippke \& Ziegelmann, 2008). Following an evaluation of the efficacy of applying the Transtheoretical model of health behavior changes, Prochaska and Velicer (1997) recommended that by matching these stages of change with the appropriate health promotion intervention organizations would be able to produce "unprecedented impacts" towards at-risk populations.

Development of the Transtheoretical model (TTM) was lead by a comparative analysis of self-changers compared to smokers in professional treatments (Prochaska \& Diclemente, 1983). In their analysis, Diclemente and Prochaska identified ten processes of change that predicted a person's chance of quitting smoking. The TTM eventually expanded to include investigations and applications to numerous health and mental health behaviors, some of which include eating disorders and obesity, alcohol and substance abuse, sedentary lifestyles, medication compliance, anxiety and panic disorders, sun exposure, physicians practicing preventive medicine, high-fat diets, HIV/AIDS prevention, cancer screenings, unplanned pregnancy prevention, and even bullying (Glanz, Rimer, \& Viswanath, 2008).

The TTM appears to be gaining more respect for its effectiveness when used with health behavior interventions than other theories. Noar, Benac, and Harris (2007) performed a meta-analysis of tailored print communications and found that TTM was the 
most commonly used theory, as well as produced greater effect sizes than interventions that did not use the constructs of the TTM. To date, the largest number of TTM-related intervention studies has focused on smoking cessation. There has been considerable evidence of the effectiveness of the TTM with smoking cessation in recruitment, retention, progress, cessation, and working with diverse group efforts (Glanz, Rimer, \& Viswanath).

TTM interventions have evolved towards efforts to treat multiple health behaviors in a population. This is important because individuals with multiple poor health behaviors are at greatest risk for chronic diseases and premature death, as well as contribute to the greatest portion of healthcare costs (Edington, 2001). TTM interventions used to treat multiple behaviors have shown to be effective with treating diabetes, increase exercise and fruit and vegetable consumption, improve overall diet, smoking cessation, and preventive health screening adherence, to name a few (Glanz, Rimer, \& Viswanath).

Some investigators have perceived little is known about the effectiveness of the Transtheoretical model when used with health behavior interventions. Consequently, Bridle et al. (2005) conducted a systematic review in order to evaluate the effectiveness of using the Transtheoretical model in interventions that attempt to modify health behaviors. Largely characterized be weak methodology, Bridle et al. concluded that results and conclusions from studies that used the Transtheoretical model were equivocal concerning the effectiveness of the model. Their review found there was little evidence with sound methodological quality as well as little evidence for the effectiveness of 
Transtheoretical model interventions aimed at facilitating health behavior change or progression through the stages. Bridle et al concluded that more studies be done that specifically determine the effectiveness of what the Transtheoretical model, and other stage-based models propose they can accomplish.

\section{Barriers and Incentives in Higher Education WHP}

Similar to the trends of WHP in business and industry, numerous institutions of higher education participate in WHP and yet few have reported data concerning perceptions of participation (Williams, 1988). Higher education WHP data were most commonly found using First Search Dissertation Abstracts. It is noteworthy, however, that studies found and reviewed from dissertation abstracts have not been published in peer-reviewed journals.

Gilmour (1993) surveyed the health interests of students and employees of a small college campus (700 employees, 4,000 students). Differences between demographic groups were found in five of the eleven health promotion programs listed in her survey. Overall, managing stress, exercising, and eating for energy were the leading responses of health interests and priorities for health promotion programming.

Eckhart, Ebro, and Claypool (1988) also used a questionnaire to assess faculty health promotion program needs and perceived barriers at the Pennsylvania community colleges. Open-ended responses were used to discover desirable program features, best time for program scheduling, preferred program methodology, and perceived barriers to implementing and participating in health promotion programs. Perceived needs for fulltime faculty included fitness programs, personal exercise programs, CPR training and 
updating, stress reduction, and health screenings. Perceived barriers to health promotion programs included multiple personal obligations, poor timing of programs or services, and differing personal philosophies.

Needs, interests, and attitudes of faculty members at Oklahoma State University were assessed prior to designing their comprehensive employee wellness program (Eckhart et al., 1988). Questionnaire content included topics of current health habits, demographics, and attitudinal questions regarding participation and interest in a wellness program. Demographics included in the assessment were gender, age, weight, height, academic rank, college within the university, and health habits. Nearly three-fourths of respondents indicated they were interested in a wellness program; while two-thirds said they would participate if the programs and services were offered. Ordered preferences of program topics were (a) exercise/fitness, (b) stress management, and (c) nutrition.

\section{Summary}

This chapter reviewed current trends in American health, as well as the financial costs imposed as a consequence of health status. Worksite health promotion was introduced and described as a means of improving the health behaviors and financial burdens of the U.S. work force. Literature concerning the benefits of current comprehensive worksite health promotion programs was evaluated, demonstrating positive outcomes of improved health behaviors, employee productivity (presenteeism and absenteeism), and an improved financial bottom line of employers.

Although literature supporting the benefits of WHP programs continues to grow today methods to improve participation have received the least attention. Assessing 
employees' interests and perceived barriers to participating in their employers WHP programs and services is especially lacking research. Numerous health promotion experts are insisting that for programs to be effective they need to be designed with consideration of the needs and interests of the eligible participants.

Many health promotion experts are also encouraging the use of more theorydriven research in efforts to improve participation rates and predictors. Health behavior theories and models are intended to aide WHP program developers in implementing interventions that will best serve the employees according to their characteristics determined by the theories and models. Health behavior theories are being used to implement health promotion programs by some employers; however, evidence of the effectiveness of their implementation with interventions is criticized as being methodologically weak.

Finally, WHP was discussed as being just as important for institutions of higher education as it is for business and industry. The environment of higher education institutions should cater well to researching and developing effective WHP programs. Although many universities and colleges may utilize comprehensive WHP programs, few have reported data concerning barriers, rates, and predictors of participation. 


\title{
CHAPTER III \\ METHODOLOGY
}

\begin{abstract}
Overview
The previous chapter provided a background of the origin, outcomes, and current status of WHP programs. Literature regarding WHP participation was also evaluated. The purpose of this chapter is to describe the sampling methods, research methods, data collection techniques, and data analysis procedures used in this study.
\end{abstract}

\section{Research Methods}

This study used an exploratory approach utilizing a questionnaire. Contents of the questionnaire were modified from a similar study performed by Kruger et al. (2007). Questions were nominal in nature, and overall percentages and statistical differences were calculated to determine differences between groups. The university's coordinator of the wellness program assisted in the development of the contents of the questionnaire. The questionnaire was distributed electronically via the university's network mail client and a secure webpage containing the questionnaire. Question responses were recorded by an electronic database upon respondent submission.

\section{Sampling}

The purpose of this study was to determine the perceived barriers and incentives of Weber State University (WSU) wellness program eligible employees for participation in wellness program services. In order to reflect the opinions of wellness program- 
eligible employees accurately, the target population for this study was defined as all wellness program-eligible employees of the university (regardless if they had previously participated in the university's wellness services). Targeting the entire population as the sample in this study was facilitated by the university's network services and employee email accounts. All employees of the university are assigned a personal email account upon hire. Participants were recruited by an email that contained an informed consent explaining the objectives and risks of the study, as well as secure access to the questionnaire.

An employee of WSU is considered eligible for wellness program services if he or she is eligible for the general benefits (health, retirement, etc.) offered by the employer. In 2007, there were approximately 1,345 employees eligible for wellness program services and policies (Weber State University, 2008). WSU is a 4-year public university with approximately 23,000 full and part-time students. In 2007, there were approximately 2,122 full and part-time employees of the university (Weber State University Institutional Research, 2007).

All data analyses were weighted to employee demographic statistics obtained from the university. This allowed the sample of participants who completed the questionnaire to more accurately reflect the demographic population of the university.

\section{Data Collection}

Data for this study were gathered using a questionnaire (see Appendix C). Respondents were incentivized by a food court coupon funded through a Weber State University Hemingway Vitality Award. The purpose of the questionnaire was to obtain 
employee input regarding their potential barriers and incentives to participation in the university's employee wellness program.

The questionnaire in this study was adapted from content of the HealthStyles Syndicated Survey Data (2004), as also used by Kruger and colleagues (2007). Kruger and colleagues used data from the HealthStyles Survey, 2004 to examine selected perceived barriers to, incentives for, and potential use of WHP programs among U.S. adults employed full-time or part-time. Question content of the HealthStyles Survey was developed by experts of several health agencies, including the Centers for Disease Control and Prevention.

With the assistance of the university's wellness program coordinator, questions from the HealthStyles Survey were modified to more accurately reflect the population of the university's employees, as opposed to uniquely reflecting the general U.S. population characterized in Kruger's study. Similarities of question content; however, allowed empirical comparison between the results of the population in this study and the U.S. population defined in Kruger's study. Construct areas examined by the questionnaire included demographics, perceived barriers and incentives for future use of wellness program services and policies, and potential use of specific WHP program services.

\section{Demographics}

Demographic categories included in the questionnaire were: gender (male or female), age group (18-29, 30-34, 35-44, 45-59, or 60-99 years), education (high school diploma or less, some college, college graduate, graduate degree [masters], or graduate degree [doctorate]), physical activity level (active, irregular, or inactive), height (nearest 
half inch), weight (nearest pound), and university employment classification (faculty, executive, adjunct faculty, professional staff, classified staff, and non-student hourly). In order for entire questionnaire responses to be compared between current wellness program participants and non-participants, respondents were asked to also indicate which employee wellness services they have participated in during the past year (health screening, fitness class/es, exercise during work, lifestyle coaching, wellness class/es, campus recreation activities, or other employee wellness resources such as WellAsured guidelines and online presentations). Respondents were considered a current wellness program participant if they reported participating in at-least a health screening, fitness class/es, or exercise during work.

Perceived Use of Employee Health Promotion Services and Policies

The following questions examined likelihood of participation in specific physical activity and nutrition services. Respondents were asked to indicate which, if any, of the following physical activity and nutrition services they currently use, or would be likely to use if offered for free at work.

Participation in physical activity services. One question addressed the respondents' likelihood to utilize any of the following physical activity services: a fitness center, on-site exercise classes, sports leagues, and paid time to exercise at work. Respondents were also asked to indicate why they were not likely to use the physical activity services not marked as an item they were likely to use.

Participation in nutrition awareness services. One question addressed the respondent's likelihood to utilize any of the following nutrition-related services: online 
tracking tools, weight loss program, personalized diet and counseling, healthy eating and cooking classes, healthy food in vending machines and cafeteria, and a weight loss support group. Also included were questions that addressed respondents' likelihood to use personalized diet and exercise counseling, health screening tests, and online tools for tracking food and exercise. Respondents were also asked to indicate why they were not likely to use the nutrition awareness services not marked as an item they were likely to use.

\section{Barriers to Participation}

Respondents were asked to indicate which, if any, of eight potential barriers would keep, or currently keep, them from participating in a free wellness program. The potential barriers included were: lack of energy, no interest, no time during the workday, no time before or after work, already involved in other similar programs or activities, not wanting to participate with co-workers, lack of self-discipline, current injury or ill-health, support of supervisor, or other barriers respondents could write-in. Respondents were asked to select any number of applicable barriers.

\section{Incentives to Participation}

Incentives for using the university's employee wellness services were assessed by having respondents indicate which, if any, of six incentives would, or currently make them interested in participating in a free wellness program at work. Potential incentives included receiving encouragement from their supervisor, getting paid time off to attend, holding programs at a convenient time, having programs held at a convenient location, 
having good coworker participation, and being able to invite family members or friends. Respondents were asked to select any number of applicable incentives.

Distribution of the questionnaire was done via the university's secure email client and network services. Each benefit-eligible employee was delivered a university bulletin (see Appendix A) including a brief introduction and instructions to the questionnaire, as well as electronic access to the questionnaire and its informed consent. By viewing the questionnaire, participants consented to the terms described in the email and informed consent. Appendix B includes a copy of the distributed bulletin containing access to the informed consent and questionnaire. Approval of the institution's Human Subjects Committee (see Appendix C) was granted prior to distributing the questionnaire.

Upon completion of the questionnaire, participants' responses were instantaneously accumulated in an electronic database. Privacy and integrity of responses were protected by granting access to the database only to the researchers of the study.

\section{Pilot Test}

In order to determine the approximate time required to complete the questionnaire, identify any issues regarding its phraseology, and determine if the analysis techniques were appropriate, a pilot test employing the questionnaire was conducted. Ten employees of a nearby higher education institution of similar characteristics were selected to complete the questionnaire as a pilot test. They were given an introduction to the questionnaire that included the purpose and scope of the study, as well as its volunteer nature and confidentiality. Time required for each participant to complete the survey was between four and five minutes. Participants were also encouraged to provide any 
feedback regarding the comprehensiveness or other concerns of the survey. The only suggestions made included minor grammatical errors.

\section{Data Analysis}

Responses to the questionnaire were recorded in an electronic database and thereafter submitted to Statistical Package for Social Sciences (SPSS), version 16 for analysis. Because the design of the web-based questionnaire did not allow submission of responses without all responses being complete, there were no respondents with missing data. Body mass index (BMI) was calculated according to the self-reported height and weight of the respondents. BMI is a ratio of a person's height in meters-squared, and their weight in kilograms. All tests of significance were compared at the .05 level.

Table 1 provides statistical details of the approaches used to answer this study's research questions. Overall percentages of perceived use of WHP services, and barriers or incentives were calculated and stratified by demographic characteristics. Statistical differences among respondents' perceived use of WHP services and perceived barriers or incentives were evaluated using logistic regression analysis. Odds ratios and 95\% confidence intervals were also calculated using logistic regression analysis. The dependent variables were each of the barriers and incentives, and the selected services and policies. The independent variables were gender, age, education, physical activity, BMI, and employment classification. Sample data were weighted by gender and education, since data from only these two demographic characteristics were available 


\section{Table 1}

Approach to Research Questions

\begin{tabular}{lll}
\hline Research question & \multicolumn{1}{c}{ Items } & \multicolumn{1}{c}{ Statistical analysis } \\
\hline $\begin{array}{l}\text { 1. What are the employee } \\
\text { perceived barriers and incentives } \\
\text { to participation in their } \\
\text { employee wellness program? }\end{array}$ & $\begin{array}{l}\text { Questionnaire } \\
\text { Items 3-6 }\end{array}$ & Descriptive statistics \\
$\begin{array}{l}\text { 2. What is the relationship } \\
\text { between demographics and the } \\
\text { perceived barriers and incentives } \\
\text { to participation? }\end{array}$ & $\begin{array}{l}\text { Questionnaire } \\
\text { Items 1, 3-6 }\end{array}$ & $\begin{array}{l}\text { Logistic regression, odds } \\
\text { ratios; descriptive group } \\
\text { percentages }\end{array}$ \\
$\begin{array}{l}\text { 3. What is the relationship } \\
\text { between the perceived barriers } \\
\text { and incentives of current } \\
\text { employee wellness participants, } \\
\begin{array}{l}\text { and the perceived barriers and } \\
\text { incentives of non-participants? }\end{array}\end{array}$ & Questionnaire & $\begin{array}{l}\text { Logistic regression, odds } \\
\text { ratios; descriptive group } \\
\text { percentages }\end{array}$ \\
\hline
\end{tabular}

from the employer. Table 2 provides the weights used when analyzing the sample data, as well as how the weights were determined.

\section{Summary}

This chapter described the methods used to complete this study. It gave details concerning the selection of the sample and how the data were collected and analyzed. This chapter also described the content development, and pilot testing of the research instrument (questionnaire). 
Table 2

Demographics Used to Weight Sample Data

\begin{tabular}{|c|c|c|c|c|c|c|}
\hline \multirow[b]{2}{*}{ Characteristic } & \multicolumn{2}{|c|}{ Population \% } & \multicolumn{2}{|c|}{ Sample \% } & \multicolumn{2}{|c|}{ Weight $^{\mathrm{a}}$} \\
\hline & Male & Female & Male & Female & Male & Female \\
\hline \multicolumn{7}{|l|}{ Employee } \\
\hline \multicolumn{7}{|l|}{ Classification } \\
\hline Executive & 2.2 & 0.6 & 1.6 & 3.2 & 1.57 & 0.19 \\
\hline Faculty & 21.7 & 13.2 & 18.4 & 17.1 & 1.18 & 0.77 \\
\hline Adjunct Faculty & 4.2 & 4.4 & 3.5 & 1.6 & 1.20 & 2.75 \\
\hline Professional Staff & 19.0 & 19.4 & 13.0 & 25.6 & 1.46 & 0.76 \\
\hline Classified Staff & 1.7 & 13.6 & 2.2 & 13.6 & 0.77 & 1.00 \\
\hline
\end{tabular}

${ }^{a}$ Weight value equals Population \% / Sample \% for each cross-tabulation of employee classification and gender. 


\section{CHAPTER IV}

\section{RESULTS}

This chapter provides the results of employee responses to the questionnaire used in this study. Specifically, this chapter presents the demographics of questionnaire respondents, as well as the employee responses to the following questionnaire constructs: (a) perceived use of physical activity services, (b) perceived use of nutrition awareness services, (c) selected barriers to participation in wellness services or policies, and (d) selected incentives to participation in wellness services or policies.

\section{Demographic Characteristics}

Table 3 provides the proportions of men and women by demographic characteristics. Twenty-five percent of employees offered the questionnaire responded to the questionnaire. Approximately $32 \%$ of the questionnaire respondents were male, and $69 \%$ were female. Most respondents were between the ages of 35 and 59 years $(21.5 \%$, $35-44 ; 38.0 \%, 45-59)$. Seventy-seven percent were college graduates, $42.7 \%$ were employed as professional Staff, $33 \%$ were employed as classified staff, $47 \%$ were active, $47 \%$ were inactive, and $65.1 \%$ were either overweight or obese.

\section{Perceived Use of Physical Activity Services}

The perceived levels of participation in physical activity services and policies are described in Table 4 in terms of agreement that respondents would use the physical activity-specific services and policies if they were offered at work. Respondents reported 
Table 3

Demographics of Survey Respondents

\begin{tabular}{|c|c|c|c|c|}
\hline Characteristic & $\begin{array}{l}\text { Overall total } \\
\text { sample count }\end{array}$ & Overall \% & $\begin{array}{l}\text { Men, } \% \\
(n=101)\end{array}$ & $\begin{array}{l}\text { Women, } \% \\
(n=220)\end{array}$ \\
\hline Total & 321 & - & 31.5 & 68.5 \\
\hline \multicolumn{5}{|l|}{ Age (years) } \\
\hline $18-29$ & 43 & 13.4 & 3.4 & 10.0 \\
\hline $30-34$ & 39 & 12.1 & 3.1 & 9.0 \\
\hline $35-44$ & 69 & 21.5 & 7.8 & 13.7 \\
\hline $45-59$ & 122 & 38.0 & 11.2 & 26.8 \\
\hline 60 or more & 48 & 15.0 & 5.9 & 9.0 \\
\hline \multicolumn{5}{|l|}{ Education } \\
\hline \multicolumn{5}{|l|}{ High school } \\
\hline diploma or less & 5 & 1.6 & 2.0 & 1.4 \\
\hline Some college & 70 & 21.8 & 12.9 & 25.9 \\
\hline College graduate & 122 & 38.0 & 36.6 & 38.6 \\
\hline Masters degree & 73 & 22.7 & 19.8 & 24.1 \\
\hline Doctorate degree & 51 & 15.9 & 28.7 & 10.0 \\
\hline \multicolumn{5}{|l|}{ Employee classification } \\
\hline Executive & 7 & 2.2 & 5.0 & 0.9 \\
\hline Faculty & 56 & 17.4 & 28.7 & 12.3 \\
\hline Adjunct faculty & 13 & 4.0 & 4.0 & 4.1 \\
\hline Professional staff & 137 & 42.7 & 45.5 & 41.4 \\
\hline Classified staff & 106 & 33.0 & 14.9 & 41.4 \\
\hline \multicolumn{5}{|l|}{ Physical activity level $^{\mathrm{a}}$} \\
\hline Active & 151 & 47.0 & 52.5 & 44.5 \\
\hline Irregular & 151 & 47.0 & 39.6 & 50.5 \\
\hline Inactive & 19 & 5.9 & 7.9 & 5.0 \\
\hline \multicolumn{5}{|l|}{$\mathrm{BMI}^{\mathrm{b}}$} \\
\hline $\begin{array}{l}\text { Underweight or } \\
\text { normal }(<25)\end{array}$ & 112 & 34.9 & 30.7 & 36.8 \\
\hline Overweight (25-29.9) & 104 & 32.4 & 37.6 & 30.0 \\
\hline Obese $(\geq 30)$ & 105 & 32.7 & 31.7 & 33.2 \\
\hline $\begin{array}{l}\text { Current wellness } \\
\text { program participant }^{\mathrm{c}}\end{array}$ & 193 & 58.3 & 72.2 & 54.6 \\
\hline
\end{tabular}

${ }^{\text {a }}$ Physical activity level was self reported as either "active", "irregular", or "inactive". 'BMI (Body Mass Index $)=$ weight $(\mathrm{kg}) /[\text { height }(\mathrm{m})]^{2}$. ${ }^{\mathrm{c}}$ Respondents were considered a "current wellness program participant" if they reported participating within the past year in at-least a health screening, fitness class, or exercise during work. 
they would use a fitness center (75.9\%), followed by health screening tests (75.6\%), paid time to exercise at work (69.6\%), diet or exercise counseling (57.5\%), and on-site exercise classes (53.0\%). Women were more likely than men to use a fitness center (OR, $2.9 ; 95 \% \mathrm{CI}, 1.6-5.4)$, and health screening tests (OR, 2.3; 95\% CI, 1.1-4.5).

Respondents aged 18-29 years were 3 to 12 times more likely than respondents 60 years or older to use each of the physical activity services and policies. Active respondents were more likely to use a fitness center than inactive respondents (OR, 4.3; 95\% CI, 1.313.8). Current wellness program participants were $2-5$ times more likely than nonparticipants to use each of these services with the exception of sports leagues, which reported as the service least likely to use by all respondents. Results did not very by BMI.

Perceived Use of Nutrition Awareness Services

Nutrition awareness services are described in Table 5 in terms of agreement that respondents would use them if they were offered at work. The most frequently reported perceived use of nutrition awareness services were healthy food choices in vending machines and cafeteria (62.0\%), followed by online tools for tracking food and exercise (57.8\%), healthy eating or cooking classes (54.8\%), a weight loss program (45.8\%), and weight loss support group (33.4\%). Women were 2-4 times more likely to use each of these nutrition awareness services and policies, and classified staff was the employee classification most likely to use these services. Respondents 35-44 years of age were 310 times more likely to use each of the nutrition awareness services with the exception of a weight loss support group, where results did not vary by age. Current wellness 
Table 4

Perceived Use of Physical Activity Services Among Benefits-Eligible Employees ${ }^{a}$

\begin{tabular}{|c|c|c|c|c|}
\hline \multirow[b]{2}{*}{ Characteristic } & \multicolumn{2}{|c|}{ Fitness center } & \multicolumn{2}{|c|}{ Onsite exercise classes } \\
\hline & $\%$ & OR $[95 \% \mathrm{CI}]$ & $\%$ & OR $[95 \% \mathrm{CI}]$ \\
\hline \multicolumn{5}{|l|}{ Sex } \\
\hline Female & 79.6 & $1.4[0.7-2.9]$ & 34.4 & $2.9[1.6-5.4]$ \\
\hline Male & 69.8 & 1.0 & 64.6 & 1.0 \\
\hline \multicolumn{5}{|l|}{ Age (years) } \\
\hline $18-29$ & 90.9 & $12.4[3.0-51.6]$ & 70.5 & $4.5[1.5-13.7]$ \\
\hline $30-34$ & 81.0 & $4.8[1.5-15.5]$ & 64.3 & $2.4[0.9-6.4]$ \\
\hline $35-44$ & 73.6 & $3.4[1.3-9.2]$ & 58.3 & $3.9[1.5-10.2]$ \\
\hline $45-59$ & 75.4 & $2.8[1.2-6.7]$ & 43.0 & $0.9[0.4-2.1]$ \\
\hline 60 or more & 60.8 & 1.0 & 45.1 & 1.0 \\
\hline \multicolumn{5}{|l|}{ Education } \\
\hline $\begin{array}{l}\text { High school } \\
\text { diploma or less }\end{array}$ & 60.0 & 1.0 & 60.0 & 1.0 \\
\hline Some college & 79.4 & $1.4[.1-15.0]$ & 67.2 & $0.4[0.0-4.4]$ \\
\hline College graduate & 74.8 & $1.5[0.1-15.0]$ & 55.1 & $0.3[0.0-2.9]$ \\
\hline Masters degree & 81.0 & $4.5[0.4-47.6]$ & 54.4 & $0.5[0.0-5.2]$ \\
\hline Doctorate degree & 67.9 & $3.3[0.3-34.5]$ & 26.4 & $0.4[0.0-4.0]$ \\
\hline \multicolumn{5}{|l|}{ Employee classification } \\
\hline Executive & 62.5 & $2.5[0.3-21.1]$ & 0.0 & $0.1[0.0-3.8]$ \\
\hline Professional staff & 79.6 & $2.8[0.8-10.2]$ & 54.4 & $1.8[0.5-5.7]$ \\
\hline Classified staff & 80.6 & $4.5[1.1-18.5]$ & 69.6 & $4.0[1.1-14.8]$ \\
\hline Faculty & 67.3 & $1.4[0.3-5.9]$ & 29.1 & $0.6[0.2-2.2]$ \\
\hline Adjunct faculty & 60.0 & 1.0 & 46.7 & 1.0 \\
\hline \multicolumn{5}{|l|}{ Physical activity level } \\
\hline Active & 82.2 & $4.3[1.3-13.8]$ & 53.2 & $0.6[0.2-2.0]$ \\
\hline Irregular & 73.9 & $3.2[1.0-9.8]$ & 53.6 & $0.5[0.2-1.6]$ \\
\hline Inactive & 42.9 & 1.0 & 47.6 & 1.0 \\
\hline \multicolumn{5}{|l|}{ BMI } \\
\hline $\begin{array}{l}\text { Underweight or } \\
\text { normal }[<25]\end{array}$ & 80.7 & $1.3[0.6-3.1]$ & 56.3 & $1.4[0.7-2.9]$ \\
\hline Overweight [25-29.9] & 71.8 & $1.0[0.4-2.0]$ & 46.8 & $0.9[0.4-1.7]$ \\
\hline Obese $[\geq 30]$ & 74.5 & 1.0 & 53.0 & 1.0 \\
\hline
\end{tabular}




\begin{tabular}{lccccc}
\hline & \multicolumn{2}{c}{ Fitness center } & & \multicolumn{2}{c}{ Onsite exercise classes } \\
\cline { 2 - 3 } \cline { 5 - 6 } Characteristic & $\%$ & OR $[95 \% \mathrm{CI}]$ & & $\%$ & OR [95\% CI] \\
\hline Wellness program & 87.0 & $\mathbf{4 . 9}[\mathbf{2 . 5 - 9 . 6}]$ & & 61.7 & $\mathbf{3 . 3}[\mathbf{1 . 8}-\mathbf{6 . 2}]$ \\
$\quad$ Participant & 60.4 & 1.0 & & 40.6 & 1.0 \\
$\quad$ Non-participant & $75.9^{*}$ & & & $53.0^{* *}$ & \\
Total & & & & & \\
\hline
\end{tabular}

Note. $\mathrm{OR}=$ odds ratio; $\mathrm{CI}=$ confidence interval. Responses reflect whether or not the respondent was "likely" to use the services if offered at work. $p$ Values are for Hosmer-Lemeshow goodness-of-fit test, where, at $\alpha=.05$, a $p$ value greater than .05 describes a significant fit of the model to the model data. Statistically significant odds ratios (CI does not include a 1.0) are depicted by bold typeface.

${ }^{a}$ Weighted percentages and data used in calculating odds ratios were adjusted to 2008 gender and employee classification statistics of Weber State University.

$* p=0.833$

$* * p=0.714$

(table continues) 


\begin{tabular}{|c|c|c|c|c|}
\hline \multirow[b]{2}{*}{ Characteristic } & \multicolumn{2}{|c|}{ Diet or exercise counseling } & \multicolumn{2}{|c|}{ Sports leagues } \\
\hline & $\%$ & OR $[95 \% \mathrm{CI}]$ & $\%$ & OR $[95 \% \mathrm{CI}]$ \\
\hline \multicolumn{5}{|l|}{ Sex } \\
\hline Female & 61.7 & $1.4[.8-2.6]$ & 16.0 & $0.5[0.3-1.1]$ \\
\hline Male & 50.8 & 1.0 & 23.8 & 1.0 \\
\hline \multicolumn{5}{|l|}{ Age (years) } \\
\hline $18-29$ & 72.7 & $5.6[1.9-15.8]$ & 26.7 & $6.1[1.4-25.9]$ \\
\hline $30-34$ & 59.5 & $2.0[.8-5.2]$ & 26.2 & $7.0[1.7-28.5]$ \\
\hline $35-44$ & 72.2 & $5.2[2.1-12.8]$ & 25.0 & $5.7[1.5-21.8]$ \\
\hline $45-59$ & 47.1 & $1.0[.5-2.2]$ & 14.9 & $3.1[0.9-11.3]$ \\
\hline 60 or more & 47.1 & 1.0 & 7.8 & 1.0 \\
\hline \multicolumn{5}{|l|}{ Education } \\
\hline $\begin{array}{l}\text { High school } \\
\text { diploma or less }\end{array}$ & 60.0 & 1.0 & 20.0 & 1.0 \\
\hline Some college & 67.6 & $0.5[.1-3.7]$ & 14.7 & $0.6[0.0-8.4]$ \\
\hline College graduate & 58.3 & $0.4[.1-2.9]$ & 19.7 & $0.7[0.1-9.1]$ \\
\hline Masters degree & 58.2 & $0.6[.1-4.9]$ & 24.1 & $1.6[0.1-20.8]$ \\
\hline Doctorate degree & 43.4 & $0.5[.1-4.1]$ & 15.1 & $0.8[0.1-11.5]$ \\
\hline \multicolumn{5}{|l|}{ Employee classification } \\
\hline Executive & 25.0 & $0.7[.1-6.1]$ & 37.5 & $2.5[0.3-22.1]$ \\
\hline Professional staff & 58.1 & $2.1[0.7-6.6]$ & 22.8 & $1.1[0.2-4.5]$ \\
\hline Classified staff & 69.9 & $4.4[1.2-15.5]$ & 15.7 & $1.6[0.3-7.9]$ \\
\hline Faculty & 49.1 & $1.7[.5-5.9]$ & 12.7 & $0.6[0.1-2.8]$ \\
\hline Adjunct faculty & 36.7 & 1.0 & 20.0 & 1.0 \\
\hline \multicolumn{5}{|l|}{ Physical activity level } \\
\hline Active & 54.8 & $1.1[0.4-3.4]$ & 21.7 & $1.2[0.3-4.3]$ \\
\hline Irregular & 61.4 & $1.3[0.4-3.8]$ & 15.7 & $0.7[0.2-2.5]$ \\
\hline Inactive & 52.4 & 1.0 & 20.0 & 1.0 \\
\hline \multicolumn{5}{|l|}{ BMI } \\
\hline $\begin{array}{l}\text { Underweight or } \\
\text { normal }[<25]\end{array}$ & 48.3 & $0.5[0.3-1.0]$ & 20.0 & $1.6[0.7-3.8]$ \\
\hline Overweight [25-29.9] & 60.4 & $1.0[0.5-1.8]$ & 22.7 & $1.9[0.8-4.2]$ \\
\hline Obese $[\geq 30]$ & 65.7 & 1.0 & 14.7 & 1.0 \\
\hline
\end{tabular}




\begin{tabular}{lcccccc}
\hline & \multicolumn{2}{c}{ Diet or exercise counseling } & & \multicolumn{2}{c}{ Sports leagues } \\
\cline { 2 - 3 } \cline { 5 - 6 } Characteristic & $\%$ & OR $[95 \% \mathrm{CI}]$ & & $\%$ & OR [95\% CI] \\
\hline Wellness program & 63.2 & $\mathbf{2 . 0}[\mathbf{1 . 1 - 3 . 6}]$ & & 19.2 & $1.0[0.5-1.9]$ \\
$\quad$ Participant & 50.0 & 1.0 & & 18.8 & 1.0 \\
$\quad$ Non-participant & $57.5^{*}$ & & & $19.0^{* *}$ & \\
Total & & & & & & \\
\hline
\end{tabular}

Note. $\mathrm{OR}=$ odds ratio $\mathrm{CI}=$ confidence interval. Responses reflect whether or not the respondent was "likely" to use the services if offered at work. $p$ Values are for Hosmer-Lemeshow goodness-of-fit test, where, at $\alpha=.05$, a $p$ value greater than .05 describes a significant fit of the model to the model data. Statistically significant odds ratios (CI does not include a 1.0) are depicted by bold typeface.

${ }^{a}$ Weighted percentages and data used in calculating odds ratios were adjusted to 2008 gender and employee classification statistics of Weber State University.

$* p=0.293$

$* * p=0.198$

(table continues) 


\begin{tabular}{|c|c|c|c|c|}
\hline \multirow[b]{2}{*}{ Characteristic } & \multicolumn{2}{|c|}{ Health screening tests } & \multicolumn{2}{|c|}{ Paid time to exercise at work } \\
\hline & $\%$ & OR $[95 \% \mathrm{CI}]$ & $\%$ & OR $[95 \% \mathrm{CI}]$ \\
\hline \multicolumn{5}{|l|}{ Sex } \\
\hline Female & 81.6 & $2.3[1.1-4.5]$ & 74.8 & $1.3[0.7-2.6]$ \\
\hline Male & 65.6 & 1.0 & 61.1 & 1.0 \\
\hline \multicolumn{5}{|l|}{ Age (years) } \\
\hline $18-29$ & 90.9 & $10.9[2.7-43.7]$ & 88.6 & $7.9[2.0-31.4]$ \\
\hline $30-34$ & 76.2 & $3.0[1.0-9.0]$ & 78.6 & $3.4[1.1-10.9]$ \\
\hline $35-44$ & 82.2 & $7.4[2.5-21.7]$ & 75.0 & $4.0[1.4-11.4]$ \\
\hline $45-59$ & 72.1 & $2.4[1.0-5.6]$ & 61.5 & $1.0[0.4-2.3]$ \\
\hline 60 or more & 60.8 & 1.0 & 58.8 & 1.0 \\
\hline \multicolumn{5}{|l|}{ Education } \\
\hline $\begin{array}{l}\text { High school } \\
\text { diploma or less }\end{array}$ & 40.0 & 1.0 & 60.0 & 1.0 \\
\hline Some college & 76.1 & $4.5[0.4-47.1]$ & 83.8 & $1.0[0.1-9.8]$ \\
\hline College graduate & 74.0 & $5.6[0.5-56.9]$ & 74.6 & $0.6[0.1-5.5]$ \\
\hline Masters degree & 86.1 & $17.3[1.6-189.4]$ & 68.4 & $1.2[0.1-11.8]$ \\
\hline Doctorate degree & 66.0 & $7.2[0.7-75.5]$ & 43.4 & $1.4[0.1-14.5]$ \\
\hline \multicolumn{5}{|l|}{ Employee classification } \\
\hline Executive & 37.5 & $0.2[0.0-2.1]$ & 25.0 & $0.2[0.0-2.4]$ \\
\hline Professional staff & 75.9 & $0.4[0.1-1.6]$ & 80.9 & $3.2[0.9-11.2]$ \\
\hline Classified staff & 78.6 & $1.0[0.2-4.4]$ & 83.3 & $6.3[1.5-26.3]$ \\
\hline Faculty & 72.7 & $1.0[0.2-4.8]$ & 38.2 & $0.5[0.1-2.0]$ \\
\hline Adjunct faculty & 79.3 & 1.0 & 41.4 & 1.0 \\
\hline \multicolumn{5}{|l|}{ Physical activity level } \\
\hline Active & 74.7 & $1.4[0.4-4.5]$ & 68.2 & $0.5[0.1-2.0]$ \\
\hline Irregular & 79.9 & $2.7[0.9-8.2]$ & 71.4 & $0.6[0.2-2.2]$ \\
\hline Inactive & 47.6 & 1.0 & 70.0 & 1.0 \\
\hline \multicolumn{5}{|l|}{ BMI } \\
\hline $\begin{array}{l}\text { Underweight or } \\
\text { normal }[<25]\end{array}$ & 76.7 & $1.6[0.7-3.5]$ & 66.7 & $0.9[0.4-2.1]$ \\
\hline Overweight [25-29.9] & 77.5 & $1.8[0.8-3.8]$ & 68.5 & $0.9[0.4-2.0]$ \\
\hline Obese $[\geq 30]$ & 72.3 & 1.0 & 74.5 & 1.0 \\
\hline
\end{tabular}




\begin{tabular}{lcccccc}
\hline & \multicolumn{2}{c}{ Health screening tests } & & \multicolumn{2}{c}{ Paid time to exercise at work } \\
\cline { 2 - 3 } \cline { 5 - 6 } Characteristic & $\%$ & OR $[95 \% \mathrm{CI}]$ & & $\%$ & OR [95\% CI] \\
\hline Wellness program & 84.5 & $\mathbf{5 . 0}[\mathbf{2 . 5 - 9 . 8}]$ & & 80.3 & $\mathbf{3 . 8}[\mathbf{1 . 9}-\mathbf{7 . 6}]$ \\
Participant & 63.8 & 1.0 & & 54.7 & 1.0 \\
Non-participant & $75.6^{*}$ & & & $69.6^{* *}$ & \\
Total & & & & & \\
\hline
\end{tabular}

Note. $\mathrm{OR}=$ odds ratio $\mathrm{CI}=$ confidence interval. Responses reflect whether or not the respondent was "likely" to use the services if offered at work. $p$ Values are for Hosmer-Lemeshow goodness-of-fit test, where, at $\alpha=.05$, a $p$ value greater than .05 describes a significant fit of the model to the model data. Statistically significant odds ratios (CI does not include a 1.0) are depicted by bold typeface.

${ }^{a}$ Weighted percentages and data used in calculating odds ratios were adjusted to 2008 gender and employee classification statistics of Weber State University.

$* p=0.365$

$* * p=0.934$

(table continues) 


\begin{tabular}{|c|c|c|}
\hline \multirow[b]{2}{*}{ Characteristic } & \multicolumn{2}{|c|}{$\begin{array}{c}\text { Confidential stress or } \\
\text { depression screening \& } \\
\text { management }\end{array}$} \\
\hline & $\%$ & OR $[95 \% \mathrm{CI}]$ \\
\hline \multicolumn{3}{|l|}{ Sex } \\
\hline Female & 54.9 & $1.8[1.0-3.2]$ \\
\hline Male & 37.3 & 1.0 \\
\hline \multicolumn{3}{|l|}{ Age (years) } \\
\hline $18-29$ & 59.1 & $3.3[1.2-8.7]$ \\
\hline $30-34$ & 47.6 & $1.7[0.7-4.2]$ \\
\hline $35-44$ & 54.8 & $3.6[1.5-8.8]$ \\
\hline $45-59$ & 45.1 & $1.7[0.8-3.6]$ \\
\hline 60 or more & 36.5 & 1.0 \\
\hline \multicolumn{3}{|l|}{ Education } \\
\hline $\begin{array}{l}\text { High school } \\
\text { diploma or less }\end{array}$ & 40.0 & 1.0 \\
\hline Some college & 54.4 & $0.7[0.1-5.7]$ \\
\hline College graduate & 51.2 & $0.8[0.1-6.5]$ \\
\hline Masters degree & 54.4 & $1.2[0.1-9.3]$ \\
\hline Doctorate degree & 26.4 & $0.7[0.1-5.7]$ \\
\hline \multicolumn{3}{|l|}{ Employee classification } \\
\hline Executive & 0.0 & 0.0 \\
\hline Professional staff & 48.5 & $0.5[0.2-1.6]$ \\
\hline Classified staff & 57.3 & $1.0[0.3-3.4]$ \\
\hline Faculty & 34.5 & $0.6[0.2-2.1]$ \\
\hline Adjunct faculty & 50.0 & 1.0 \\
\hline \multicolumn{3}{|l|}{ Physical activity level } \\
\hline Active & 46.5 & $0.5[0.2-1.5]$ \\
\hline Irregular & 49.4 & $0.6[0.2-1.7]$ \\
\hline Inactive & 52.4 & 1.0 \\
\hline \multicolumn{3}{|l|}{ BMI } \\
\hline $\begin{array}{l}\text { Underweight or } \\
\text { normal }[<25]\end{array}$ & 44.5 & $1.0[0.5-1.9]$ \\
\hline Overweight [25-29.9] & 50.0 & $1.3[0.7-2.4]$ \\
\hline Obese $[\geq 30]$ & 50.0 & 1.0 \\
\hline
\end{tabular}




\begin{tabular}{lcc}
\hline & \multicolumn{2}{c}{$\begin{array}{c}\text { Confidential stress or } \\
\text { depression screening \& } \\
\text { management }\end{array}$} \\
\cline { 2 - 3 } Characteristic & $\%$ & OR [95\% CI] \\
\hline Wellness program & 54.6 & $\mathbf{2 . 3}[\mathbf{1 . 3}-\mathbf{4 . 1}]$ \\
$\quad$ Participant & 39.1 & 1.0 \\
Non-participant & $48.2^{*}$ & \\
Total & & \\
\hline
\end{tabular}

Note. $\mathrm{OR}=$ odds ratio $; \mathrm{CI}=$ confidence interval. Responses reflect whether or not the respondent was "likely" to use the services if offered at work. $p$ Values are for Hosmer-Lemeshow goodness-of-fit test, where, at $\alpha=.05$, a $p$ value greater than .05 describes a significant fit of the model to the model data.

Statistically significant odds ratios (CI does not include a 1.0) are depicted by bold typeface.

${ }^{a}$ Weighted percentages and data used in calculating odds ratios were adjusted to 2008 gender and employee classification statistics of Weber State University.

$* p=0.412$ 
Table 5

Perceived Use of Nutrition Awareness Services Among Benefits-Eligible Employees

\begin{tabular}{|c|c|c|c|c|}
\hline \multirow[b]{2}{*}{ Characteristic } & \multicolumn{2}{|c|}{$\begin{array}{c}\text { Online tools for tracking food } \\
\text { and exercise }\end{array}$} & \multicolumn{2}{|c|}{$\begin{array}{c}\text { Healthy food choices in } \\
\text { vending machines and } \\
\text { cafeteria }\end{array}$} \\
\hline & $\%$ & OR $[95 \% \mathrm{CI}]$ & $\%$ & OR $[95 \% \mathrm{CI}]$ \\
\hline \multicolumn{5}{|l|}{ Sex } \\
\hline Female & 65.0 & $2.0[1.1-3.5]$ & 71.4 & $3.5[1.9-6.5]$ \\
\hline Male & 46.0 & 1.0 & 46.8 & 1.0 \\
\hline \multicolumn{5}{|l|}{ Age (years) } \\
\hline $18-29$ & 59.1 & $2.0[0.8-5.0]$ & 72.7 & $3.7[1.3-10.5]$ \\
\hline $30-34$ & 61.9 & $2.3[0.9-5.8]$ & 64.3 & $2.1[0.8-5.5]$ \\
\hline $35-44$ & 65.3 & $3.0[1.3-7.0]$ & 70.8 & $2.6[1.1-6.3]$ \\
\hline $45-59$ & 59.0 & $1.8[0.9-3.8]$ & 57.9 & $1.1[0.5-2.3]$ \\
\hline 60 or more & 41.2 & 1.0 & 49.0 & 1.0 \\
\hline \multicolumn{5}{|l|}{ Education } \\
\hline $\begin{array}{l}\text { High school } \\
\text { diploma or less }\end{array}$ & 40.0 & 1.0 & 40.0 & 1.0 \\
\hline Some college & 72.1 & $1.5[0.2-11.9]$ & 64.7 & $1.4[0.2-11.1]$ \\
\hline College graduate & 59.5 & $1.2[0.1-9.4]$ & 59.8 & $1.8[0.2-14.6]$ \\
\hline Masters degree & 53.2 & $1.1[0.1-9.4]$ & 70.9 & $5.0[0.6-42.9]$ \\
\hline Doctorate degree & 45.3 & $2.0[0.2-17.8]$ & 53.8 & $3.8[0.4-33.9]$ \\
\hline \multicolumn{5}{|l|}{ Employee classification } \\
\hline Executive & 25.0 & $0.3[0.0-2.6]$ & 44.4 & $1.9[0.3-13.0]$ \\
\hline Professional staff & 60.3 & $1.3[0.4-3.8]$ & 61.0 & $1.7[0.5-5.6]$ \\
\hline Classified staff & 70.9 & $1.7[0.5-5.7]$ & 70.9 & $3.3[0.9-12.2]$ \\
\hline Faculty & 41.8 & $0.6[0.2-1.9]$ & 57.1 & $2.2[0.6-8.1]$ \\
\hline Adjunct faculty & 41.4 & 1.0 & 50.0 & 1.0 \\
\hline \multicolumn{5}{|l|}{ Physical activity level } \\
\hline Active & 55.1 & $0.8[0.2-2.5]$ & 56.3 & $0.3[0.1-1.1]$ \\
\hline Irregular & 60.1 & $0.8[0.2-2.4]$ & 66.2 & $0.4[0.1-1.5]$ \\
\hline Inactive & 61.9 & 1.0 & 76.2 & 1.0 \\
\hline \multicolumn{5}{|l|}{ BMI } \\
\hline $\begin{array}{c}\text { Underweight or } \\
\text { normal }[<25]\end{array}$ & 50.0 & $0.6[0.3-1.1]$ & 51.3 & $0.4[0.2-0.9]$ \\
\hline Overweight [25-29.9] & 58.2 & $0.7[0.2-2.4]$ & 64.5 & $0.9[0.4-1.7]$ \\
\hline
\end{tabular}




\begin{tabular}{|c|c|c|c|c|}
\hline \multirow[b]{2}{*}{ Characteristic } & \multicolumn{2}{|c|}{$\begin{array}{c}\text { Online tools for tracking food } \\
\text { and exercise }\end{array}$} & \multicolumn{2}{|c|}{$\begin{array}{c}\text { Healthy food choices in } \\
\text { vending machines and } \\
\text { cafeteria }\end{array}$} \\
\hline & $\%$ & OR $[95 \% \mathrm{CI}]$ & $\%$ & OR $[95 \% \mathrm{CI}]$ \\
\hline Obese $[\geq 30]$ & 67.6 & 1.0 & 72.3 & 1.0 \\
\hline \multicolumn{5}{|l|}{ Wellness program } \\
\hline Participant & 62.4 & $1.6[0.9-2.7]$ & 64.2 & $1.3[0.8-2.4]$ \\
\hline Non-participant & 51.8 & 1.0 & 59.0 & 1.0 \\
\hline Total & $57.8^{*}$ & & $62.0^{* *}$ & \\
\hline
\end{tabular}

Note. $\mathrm{OR}=$ odds ratio $\mathrm{CI}=$ confidence interval. Responses reflect whether or not the respondent was "likely" to use the services if offered at work. $p$ Values are for Hosmer-Lemeshow goodness-of-fit test, where, at $\alpha=.05$, a $p$ value greater than .05 describes a significant fit of the model to the model data. Statistically significant odds ratios (CI does not include a 1.0) are depicted by bold typeface.

${ }^{a}$ Weighted percentages and data used in calculating odds ratios were adjusted to 2008 gender and employee classification statistics of Weber State University.

$* p=0.854$

$* * p=0.128$

(table continues) 


\begin{tabular}{|c|c|c|c|c|}
\hline \multirow[b]{2}{*}{ Characteristic } & \multicolumn{2}{|c|}{$\begin{array}{l}\text { Healthy eating or cooking } \\
\text { classes }\end{array}$} & \multicolumn{2}{|c|}{ Weight loss program } \\
\hline & $\%$ & $\mathrm{OR}[95 \% \mathrm{CI}]$ & $\%$ & OR $[95 \% \mathrm{CI}]$ \\
\hline \multicolumn{5}{|l|}{ Sex } \\
\hline Female & 63.1 & $2.4[1.3-4.4]$ & 52.4 & $2.5[1.3-4.9]$ \\
\hline Male & 42.1 & 1.0 & 35.2 & 1.0 \\
\hline \multicolumn{5}{|l|}{ Age (years) } \\
\hline $18-29$ & 61.4 & $4.6[1.7-12.6]$ & 40.9 & $1.3[0.5-4.0]$ \\
\hline $30-34$ & 57.1 & 3.3 [1.3-8.6] & 72.9 & $0.8[0.3-2.3]$ \\
\hline $35-44$ & 69.4 & $10.1[3.8-26.4]$ & 58.3 & $2.6[1.0-6.8]$ \\
\hline $45-59$ & 54.1 & $2.8[1.3-6.2]$ & 41.0 & $0.6[0.3-1.4]$ \\
\hline 60 or more & 30.8 & 1.0 & 46.2 & 1.0 \\
\hline \multicolumn{5}{|l|}{ Education } \\
\hline $\begin{array}{l}\text { High school } \\
\text { diploma or less }\end{array}$ & 40.0 & 1.0 & 40.0 & 1.0 \\
\hline Some college & 63.2 & $0.8[0.1-6.7]$ & 64.7 & $0.2[0.0-4.6]$ \\
\hline College graduate & 57.1 & $0.8[0.1-6.3]$ & 43.3 & $0.2[0.0-3.3]$ \\
\hline Masters degree & 58.2 & $1.2[0.1-10.7]$ & 46.8 & $0.4[0.0-8.1]$ \\
\hline Doctorate degree & 35.8 & $0.9[0.1-8.0]$ & 26.4 & $0.5[0.0-9.8]$ \\
\hline \multicolumn{5}{|l|}{ Employee classification } \\
\hline Executive & 0.0 & $0.04[0.0-4.7]$ & 25.0 & $0.9[0.1-9.4]$ \\
\hline Professional staff & 59.6 & $1.9[0.6-5.9]$ & 44.9 & $2.1[0.6-8.2]$ \\
\hline Classified staff & 65.0 & $2.7[0.8-9.6]$ & 66.0 & $5.9[1.3-25.9]$ \\
\hline Faculty & 41.8 & $1.3[0.4-4.9]$ & 25.5 & $0.7[0.2-2.9]$ \\
\hline Adjunct faculty & 36.7 & 1.0 & 23.3 & 1.0 \\
\hline \multicolumn{5}{|l|}{ Physical activity level } \\
\hline Active & 53.5 & $0.5[0.1-1.6]$ & 40.5 & $0.7[0.2-2.3]$ \\
\hline Irregular & 55.2 & $0.4[0.1-1.5]$ & 49.0 & $0.7[0.2-2.2]$ \\
\hline Inactive & 65.0 & 1.0 & 60.0 & 1.0 \\
\hline \multicolumn{5}{|l|}{ BMI } \\
\hline $\begin{array}{c}\text { Underweight or } \\
\text { normal }[<25]\end{array}$ & 50.4 & $0.9[0.5-1.8]$ & 22.5 & $0.1[0.1-0.3]$ \\
\hline Overweight [25-29.9] & 55.0 & $1.1[0.6-2.1]$ & 52.3 & $0.7[0.3-1.4]$ \\
\hline Obese $[\geq 30]$ & 60.8 & 1.0 & 66.3 & 1.0 \\
\hline
\end{tabular}




\begin{tabular}{|c|c|c|c|c|}
\hline \multirow[b]{2}{*}{ Characteristic } & \multicolumn{2}{|c|}{$\begin{array}{l}\text { Healthy eating or cooking } \\
\text { classes }\end{array}$} & \multicolumn{2}{|c|}{ Weight loss program } \\
\hline & $\%$ & OR $[95 \% \mathrm{CI}]$ & $\%$ & OR $[95 \% \mathrm{CI}]$ \\
\hline \multicolumn{5}{|l|}{ Wellness program } \\
\hline Participant & 61.9 & $2.1[1.2-3.8]$ & 49.2 & $1.2[0.7-2.3]$ \\
\hline Non-participant & 45.3 & 1.0 & 41.0 & 1.0 \\
\hline Total & $54.8^{*}$ & & $45.8^{* *}$ & \\
\hline
\end{tabular}

Note. $\mathrm{OR}=$ odds ratio $\mathrm{CI}=$ confidence interval. Responses reflect whether or not the respondent was "likely" to use the services if offered at work. $p$ Values are for Hosmer-Lemeshow goodness-of-fit test, where, at $\alpha=.05$, a $p$ value greater than .05 describes a significant fit of the model to the model data. Statistically significant odds ratios (CI does not include a 1.0) are depicted by bold typeface.

${ }^{a}$ Weighted percentages and data used in calculating odds ratios were adjusted to 2008 gender and employee classification statistics of Weber State University.

$* p=0.472$

$* * p=0.235$

(table continues) 


\begin{tabular}{|c|c|c|}
\hline \multirow[b]{2}{*}{ Characteristic } & \multicolumn{2}{|c|}{ Weight loss support group } \\
\hline & $\%$ & OR $[95 \% \mathrm{CI}]$ \\
\hline \multicolumn{3}{|l|}{ Sex } \\
\hline Female & 43.0 & $4.2[2.1-8.3]$ \\
\hline Male & 17.6 & 1.0 \\
\hline \multicolumn{3}{|l|}{ Age (years) } \\
\hline $18-29$ & 29.5 & $1.2[0.4-3.6]$ \\
\hline $30-34$ & 35.7 & $1.1[0.4-3.3]$ \\
\hline $35-44$ & 40.3 & $2.1[0.8-5.6]$ \\
\hline $45-59$ & 32.8 & $0.9[0.4-2.1]$ \\
\hline 60 or more & 27.5 & 1.0 \\
\hline \multicolumn{3}{|l|}{ Education } \\
\hline $\begin{array}{l}\text { High school } \\
\text { diploma or less }\end{array}$ & 40.0 & 1.0 \\
\hline Some college & 47.1 & $0.2[0.0-2.9]$ \\
\hline College graduate & 34.6 & $0.2[0.0-3.1]$ \\
\hline Masters degree & 32.9 & $0.4[0.0-5.5]$ \\
\hline Doctorate degree & 13.2 & $0.2[0.0-3.9]$ \\
\hline \multicolumn{3}{|l|}{ Employee classification } \\
\hline Executive & 0.0 & $0.3[0.0-31.7]$ \\
\hline Professional staff & 32.4 & $2.2[0.5-9.6]$ \\
\hline Classified staff & 52.9 & $5.4[1.1-26.1]$ \\
\hline Faculty & 14.5 & $1.1[0.2-5.3]$ \\
\hline Adjunct faculty & 13.3 & 1.0 \\
\hline \multicolumn{3}{|l|}{ Physical activity level } \\
\hline Active & 29.3 & $0.3[0.1-1.0]$ \\
\hline Irregular & 34.6 & $0.3[0.1-0.8]$ \\
\hline Inactive & 57.1 & 1.0 \\
\hline \multicolumn{3}{|l|}{ BMI } \\
\hline $\begin{array}{l}\text { Underweight or } \\
\text { normal }[<25]\end{array}$ & 16.8 & $0.3[0.1-0.6]$ \\
\hline Overweight [25-29.9] & 37.3 & $1.0[0.5-1.9]$ \\
\hline Obese $[\geq 30]$ & 48.0 & 1.0 \\
\hline
\end{tabular}




\begin{tabular}{lcl}
\hline & \multicolumn{2}{c}{ Weight loss support group } \\
\cline { 2 - 3 } Characteristic & $\%$ & \multicolumn{1}{c}{ OR $[95 \% \mathrm{CI}]$} \\
\hline Wellness program & 37.3 & $1.5[0.8-2.8]$ \\
Participant & 28.3 & 1.0 \\
Non-participant & $33.4^{*}$ & \\
Total & \\
\hline
\end{tabular}

Note. $\mathrm{OR}=$ odds ratio; $\mathrm{CI}=$ confidence interval. Responses reflect whether or not the respondent was "likely" to use the services if offered at work. $p$ Values are for Hosmer-Lemeshow goodness-of-fit test, where, at $\alpha=.05$, a $p$ value greater than .05 describes a significant fit of the model to the model data.

Statistically significant odds ratios (CI does not include a 1.0) are depicted by bold typeface.

${ }^{\mathrm{a}}$ Weighted percentages and data used in calculating odds ratios were adjusted to 2008 gender and employee classification statistics of Weber State University.

$* p=0.480$

participants were more likely than non-participants to use healthy eating or cooking classes (OR, 2.1; 95\% CI, 1.2-3.8); however, likelihood to use the other nutrition awareness services did not vary by whether respondents were a current wellness program participant or not. Results did not vary by education, physical activity level, or BMI.

\section{Selected Barriers to Wellness Services}

The most commonly reported barriers to using employee wellness services (Table 6) were no time during work day (60.2\%), lack of self-discipline (27.7\%), and already involved in other programs or activities (24.4\%). Women were more likely than men to report lack of energy (OR, 4.5; 95\% CI, 1.7-11.9) and no time during work day (OR, 2.6; 95\% CI, 1.4-4.8). Respondents 30-34 years, classified staff, and women were most likely 
Table 6

Selected Barriers to Wellness Services Among Benefits-Eligible Employees

\begin{tabular}{|c|c|c|c|c|}
\hline \multirow[b]{2}{*}{ Characteristic } & \multicolumn{2}{|c|}{ Lack of energy } & \multicolumn{2}{|c|}{ No interest } \\
\hline & $\%$ & OR $[95 \% \mathrm{CI}]$ & $\%$ & OR $[95 \% \mathrm{CI}]$ \\
\hline \multicolumn{5}{|l|}{ Sex } \\
\hline Female & 21.4 & $4.5[1.7-11.9]$ & 14.6 & $1.4[0.6-3.3]$ \\
\hline Male & 8.7 & 1.0 & 14.3 & 1.0 \\
\hline \multicolumn{5}{|l|}{ Age (years) } \\
\hline $18-29$ & 15.6 & $2.1[0.5-9.2]$ & 11.1 & $0.3[0.1-1.2]$ \\
\hline $30-34$ & 33.3 & $5.1[1.4-18.4]$ & 9.5 & $0.2[0.1-0.9]$ \\
\hline $35-44$ & 12.5 & $0.9[0.2-3.3]$ & 9.7 & $0.2[0.1-0.6]$ \\
\hline $45-59$ & 14.9 & $1.1[0.3-3.5]$ & 14.8 & $0.5[0.2-1.3]$ \\
\hline 60 or more & 11.8 & 1.0 & 26.9 & 1.0 \\
\hline \multicolumn{5}{|l|}{ Education } \\
\hline $\begin{array}{l}\text { High school } \\
\text { diploma or less }\end{array}$ & 40.0 & 1.0 & 40.0 & 1.0 \\
\hline Some college & 25.0 & $0.6[0.1-7.0]$ & 5.9 & $0.1[0.0-1.0]$ \\
\hline College graduate & 14.3 & $0.3[0.0-3.5]$ & 12.6 & $0.3[0.0-2.3]$ \\
\hline Masters degree & 16.5 & $0.5[0.0-6.0]$ & 16.5 & $0.2[0.0-1.9]]$ \\
\hline Doctorate degree & 7.5 & $0.3[0.0-3.8]$ & 24.5 & $0.2[0.0-2.0]$ \\
\hline \multicolumn{5}{|l|}{ Employee classification } \\
\hline Executive & 0.0 & 0.0 & 22.2 & $1.4[0.1-16.3]$ \\
\hline Professional staff & 17.6 & $1.3[0.4-4.2]$ & 10.3 & $0.4[0.1-1.4]$ \\
\hline Classified staff & 23.3 & $1.1[0.3-4.5]$ & 8.7 & $0.2[0.1-1.2]$ \\
\hline Faculty & 12.7 & 1.0 & 25.5 & $1.0[0.2-4.7]$ \\
\hline Adjunct faculty & 0.0 & 0.0 & 31.0 & 1.0 \\
\hline \multicolumn{5}{|l|}{ Physical activity level } \\
\hline Active & 5.7 & $0.1[0.0-0.2]$ & 12.7 & 1.0 \\
\hline Irregular & 24.7 & $0.3[0.1-1.0]$ & 18.2 & $2.0[1.0-4.0]$ \\
\hline Inactive & 38.1 & 1.0 & 0.0 & 0.0 \\
\hline \multicolumn{5}{|l|}{ BMI } \\
\hline $\begin{array}{l}\text { Underweight or } \\
\text { normal }[<25]\end{array}$ & 8.3 & $0.2[0.1-0.6]$ & 15.8 & $0.9[0.3-2.6]$ \\
\hline Overweight [25-29.9] & 14.5 & $0.4[0.2-0.9]$ & 16.4 & $1.5[0.6-3.9]$ \\
\hline Obese $[\geq 30]$ & 27.7 & 1.0 & 10.9 & 1.0 \\
\hline
\end{tabular}




\begin{tabular}{lcccccc}
\hline & \multicolumn{2}{c}{ Lack of energy } & & \multicolumn{2}{c}{ No interest } \\
\cline { 2 - 3 } \cline { 5 - 6 } Characteristic & $\%$ & OR $[95 \% \mathrm{CI}]$ & & $\%$ & OR [95\% CI] \\
\hline Wellness program & 18.1 & $1.2[0.5-2.6]$ & & 14.0 & $1.4[0.6-3.2]$ \\
$\quad$ Participant & 13.8 & 1.0 & & 15.1 & 1.0 \\
$\quad$ Non-participant & $16.6^{*}$ & & & $14.5^{* *}$ & \\
Total & & & & & & \\
\hline
\end{tabular}

Note. $\mathrm{OR}=$ odds ratio; $\mathrm{CI}=$ confidence interval. Respondents selected a yes response for as many barriers they felt keep or would keep them from participating in a free employee wellness program. $p$ Values are for Hosmer-Lemeshow goodness-of-fit test, where, at $\alpha=.05$, a $p$ value greater than .05 describes a significant fit of the model to the model data. Statistically significant odds ratios (CI does not include a 1.0) are depicted by bold typeface.

${ }^{a}$ Weighted percentages and data used in calculating odds ratios were adjusted to 2008 gender and employee classification statistics of Weber State University.

$* p=0.296$

$* * p=0.728$ 


\begin{tabular}{|c|c|c|c|c|}
\hline \multirow[b]{2}{*}{ Characteristic } & \multicolumn{2}{|c|}{ No time during work day } & \multicolumn{2}{|c|}{$\begin{array}{l}\text { Already involved in other, } \\
\text { similar activities }\end{array}$} \\
\hline & $\%$ & OR $[95 \% \mathrm{CI}]$ & $\%$ & OR $[95 \% \mathrm{CI}]$ \\
\hline \multicolumn{5}{|l|}{ Sex } \\
\hline Female & 68.9 & $2.6[1.4-4.8]$ & 22.8 & $1.1[0.5-2.2]$ \\
\hline Male & 46.0 & 1.0 & 27.2 & 1.0 \\
\hline \multicolumn{5}{|l|}{ Age (years) } \\
\hline $18-29$ & 63.6 & $1.5[0.5-4.4]$ & 15.9 & $0.4[0.1-1.5]$ \\
\hline $30-34$ & 54.8 & $0.8[0.3-2.3]$ & 23.8 & $0.6[0.2-1.8]$ \\
\hline $35-44$ & 61.1 & $1.3[0.5-3.3]$ & 18.1 & $0.4[0.1-1.1]$ \\
\hline $45-59$ & 63.1 & $1.5[0.6-3.4]$ & 27.0 & $0.9[0.4-2.1]$ \\
\hline 60 or more & 52.9 & 1.0 & 36.5 & 1.0 \\
\hline \multicolumn{5}{|l|}{ Education } \\
\hline $\begin{array}{l}\text { High school } \\
\text { diploma or less }\end{array}$ & 100.0 & 1.0 & 0.0 & 0.0 \\
\hline Some college & 75.0 & 0.0 & 13.2 & $0.2[0.1-1.0]$ \\
\hline College graduate & 60.6 & 0.0 & 18.9 & $0.4[0.1-1.2]$ \\
\hline Masters degree & 54.4 & 0.0 & 27.8 & $0.2[0.1-0.7]$ \\
\hline Doctorate degree & 45.3 & 0.0 & 50.9 & 1.0 \\
\hline \multicolumn{5}{|l|}{ Employee classification } \\
\hline Executive & 44.4 & $11.6[1.4-93.7]$ & 37.5 & $0.2[0.0-1.4]$ \\
\hline Professional staff & 59.1 & $11.3[3.1-41.2]$ & 16.1 & $0.1[0.0-0.2]$ \\
\hline Classified staff & 75.5 & $11.6[2.9-47.4]$ & 14.6 & $0.1[0.0-0.3]$ \\
\hline Faculty & 52.7 & $11.9[2.8-50.2]$ & 40.0 & $0.1[0.0-0.3]$ \\
\hline Adjunct faculty & 31.0 & 1.0 & 69.0 & 1.0 \\
\hline \multicolumn{5}{|l|}{ Physical activity level } \\
\hline Active & 46.8 & $2.2[0.8-6.6]$ & 35.0 & 1.0 \\
\hline Irregular & 76.6 & $6.6[2.3-19.4]$ & 17.0 & $0.4[0.2-0.8]$ \\
\hline Inactive & 40.0 & 1.0 & 0.0 & 0.0 \\
\hline \multicolumn{5}{|l|}{ BMI } \\
\hline $\begin{array}{l}\text { Underweight or } \\
\text { normal }[<25]\end{array}$ & 49.2 & $0.5[0.3-1.1]$ & 29.2 & $0.5[0.2-1.3]$ \\
\hline Overweight [25-29.9] & 68.2 & $1.4[0.7-2.9]$ & 25.2 & $0.8[0.4-1.8]$ \\
\hline Obese $[\geq 30]$ & 64.7 & 1.0 & 18.6 & 1.0 \\
\hline
\end{tabular}




\begin{tabular}{|c|c|c|c|c|}
\hline \multirow[b]{2}{*}{ Characteristic } & \multicolumn{2}{|c|}{ No Time During Work Day } & \multicolumn{2}{|c|}{$\begin{array}{l}\text { Already Involved in Other, } \\
\text { Similar Activities }\end{array}$} \\
\hline & $\%$ & OR $[95 \% \mathrm{CI}]$ & $\%$ & OR $[95 \% \mathrm{CI}]$ \\
\hline \multicolumn{5}{|l|}{ Wellness Program } \\
\hline Participant & 59.6 & $0.7[0.4-1.2]$ & 22.8 & $1.1[0.5-2.2]$ \\
\hline Non-Participant & 61.6 & 1.0 & 26.8 & 1.0 \\
\hline Total & $60.2^{*}$ & & $24.4^{* *}$ & \\
\hline
\end{tabular}

Note. $\mathrm{OR}=$ odds ratio $\mathrm{CI}=$ confidence interval. Respondents selected a yes response for as many barriers they felt keep or would keep them from participating in a free employee wellness program. $p$ Values are for Hosmer-Lemeshow goodness-of-fit test, where, at $\alpha=.05$, a $p$ value greater than .05 describes a significant fit of the model to the model data. Statistically significant odds ratios (CI does not include a $1.0)$ are depicted by bold typeface.

${ }^{a}$ Weighted percentages and data used in calculating odds ratios were adjusted to 2008 gender and employee classification statistics of Weber State University.

$* p=0.343$

$* * p=0.642$

(table continues) 


\begin{tabular}{|c|c|c|c|c|}
\hline \multirow[b]{2}{*}{ Characteristic } & \multicolumn{2}{|c|}{$\begin{array}{l}\text { Don't want to participate with } \\
\text { other employees }\end{array}$} & \multicolumn{2}{|c|}{ Lack of self-discipline } \\
\hline & $\%$ & OR $[95 \% \mathrm{CI}]$ & $\%$ & OR $[95 \% \mathrm{CI}]$ \\
\hline \multicolumn{5}{|l|}{ Sex } \\
\hline Female & 10.7 & $2.6[0.8-8.3]$ & 30.1 & $1.2[0.6-2.4]$ \\
\hline Male & 5.6 & 1.0 & 23.2 & 1.0 \\
\hline \multicolumn{5}{|l|}{ Age (years) } \\
\hline $18-29$ & 2.3 & $0.1[0.0-0.9]$ & 22.7 & $2.5[0.7-8.8]$ \\
\hline $30-34$ & 7.1 & $0.4[0.1-1.8]$ & 35.7 & $4.4[1.4-14.1]$ \\
\hline $35-44$ & 5.6 & $0.2[0.1-1.0]$ & 38.9 & $5.5[1.9-16.0]$ \\
\hline $45-59$ & 10.7 & $0.6[0.2-1.8]$ & 26.2 & $2.3[0.9-6.3]$ \\
\hline 60 or more & 15.7 & 1.0 & 13.7 & 1.0 \\
\hline \multicolumn{5}{|l|}{ Education } \\
\hline $\begin{array}{l}\text { High school } \\
\text { diploma or less }\end{array}$ & 0.0 & 0.0 & 40.0 & 1.0 \\
\hline Some college & 10.3 & $0.9[0.2-3.5]$ & 41.2 & $1.0[0.1-10.0]$ \\
\hline College graduate & 7.9 & $0.8[0.2-2.7]$ & 29.1 & $0.8[0.1-7.5]$ \\
\hline Masters degree & 10.1 & $1.0[0.3-3.6]$ & 24.1 & $0.9[0.1-8.7]$ \\
\hline Doctorate degree & 7.5 & 1.0 & 11.3 & $0.2[0.0-2.4]$ \\
\hline \multicolumn{5}{|l|}{ Employee classification } \\
\hline Executive & 22.2 & $0.8[0.1-10.2]$ & 22.2 & $8.4[0.6-110.3]$ \\
\hline Professional staff & 8.1 & $0.4[0.1-2.3]$ & 25.0 & $5.0[1.0-26.3]$ \\
\hline Classified staff & 9.7 & $0.4[0.1-2.9]$ & 38.8 & $8.8[1.5-50.8]$ \\
\hline Faculty & 8.1 & $0.1[0.0-0.8]$ & 23.6 & $12.6[2.1-74.5]$ \\
\hline Adjunct faculty & 20.0 & 1.0 & 10.0 & 1.0 \\
\hline \multicolumn{5}{|l|}{ Physical activity level } \\
\hline Active & 8.2 & $1.2[0.2-8.0]$ & 13.9 & $0.3[0.1-1.0]$ \\
\hline Irregular & 9.7 & $1.2[0.2-7.6]$ & 40.5 & $1.2[0.4-3.6]$ \\
\hline Inactive & 9.5 & 1.0 & 38.1 & 1.0 \\
\hline \multicolumn{5}{|l|}{ BMI } \\
\hline $\begin{array}{l}\text { Underweight or } \\
\text { normal }[<25]\end{array}$ & 6.7 & $0.5[0.2-1.9]$ & 17.6 & $0.7[0.3-1.6]$ \\
\hline Overweight [25-29.9] & 10.8 & $0.9[0.3-2.5]$ & 33.6 & $1.3[0.7-2.6]$ \\
\hline Obese $[\geq 30]$ & 9.8 & 1.0 & 33.3 & 1.0 \\
\hline
\end{tabular}




\begin{tabular}{lcccccc}
\hline & \multicolumn{2}{c}{$\begin{array}{c}\text { Don't want to participate with } \\
\text { other employees }\end{array}$} & & \multicolumn{2}{c}{ Lack of self-discipline } \\
\cline { 2 - 3 } \cline { 5 - 7 } Characteristic & $\%$ & OR $[95 \% \mathrm{CI}]$ & & $\%$ & OR [95\% CI] \\
\hline Wellness program & 8.3 & $0.6[0.2-1.7]$ & & 26.4 & $0.9[0.5-1.7]$ \\
$\quad$ Participant & 9.4 & 1.0 & & 29.5 & 1.0 \\
$\quad$ Non-participant & $8.7^{*}$ & & & $27.7^{* *}$ & \\
Total & & & & & & \\
\hline
\end{tabular}

Note. $\mathrm{OR}=$ odds ratio $\mathrm{CI}=$ confidence interval. Respondents selected a yes response for as many barriers they felt keep or would keep them from participating in a free employee wellness program. $p$ Values are for Hosmer-Lemeshow goodness-of-fit test, where, at $\alpha=.05$, a $p$ value greater than .05 describes a significant fit of the model to the model data. Statistically significant odds ratios (CI does not include a 1.0) are depicted by bold typeface.

${ }^{a}$ Weighted percentages and data used in calculating odds ratios were adjusted to 2008 gender and employee classification statistics of Weber State University.

$* p=0.867$

$* * p=0.705$

(table continues) 


\begin{tabular}{|c|c|c|c|c|}
\hline \multirow[b]{2}{*}{ Characteristic } & \multicolumn{2}{|c|}{ Current injury or ill-health } & \multicolumn{2}{|c|}{ Support of supervisor } \\
\hline & $\%$ & OR $[95 \% \mathrm{CI}]$ & $\%$ & OR $[95 \% \mathrm{CI}]$ \\
\hline \multicolumn{5}{|l|}{ Sex } \\
\hline Female & 15.0 & $0.9[0.4-1.9]$ & 15.5 & $0.8[0.3-2.0]$ \\
\hline Male & 11.1 & 1.0 & 13.5 & 1.0 \\
\hline \multicolumn{5}{|l|}{ Age (years) } \\
\hline $18-29$ & 22.7 & $0.4[0.1-2.0]$ & 8.9 & $1.5[0.4-5.6]$ \\
\hline $30-34$ & 11.9 & $1.2[0.3-4.1]$ & 19.0 & $0.8[0.2-3.6]$ \\
\hline $35-44$ & 15.1 & $0.7[0.2-2.4]$ & 15.3 & $1.2[0.3-4.4]$ \\
\hline $45-59$ & 9.9 & $0.8[0.3-2.5]$ & 15.6 & $0.8[0.2-2.6]$ \\
\hline 60 or more & 13.5 & 1.0 & 15.4 & 1.0 \\
\hline \multicolumn{5}{|l|}{ Education } \\
\hline $\begin{array}{l}\text { High school } \\
\text { diploma or less }\end{array}$ & 0.0 & 0.0 & 0.0 & 0.0 \\
\hline Some college & 23.5 & $5.9[1.3-26.2]$ & 20.6 & $4.0[1.4-11.6]$ \\
\hline College graduate & 18.9 & $3.0[0.7-12.8]$ & 11.8 & $2.7[1.0-7.2]$ \\
\hline Masters degree & 7.6 & $6.8[1.6-28.9]$ & 22.8 & 1.0 \\
\hline Doctorate degree & 0.0 & 1.0 & 3.8 & 0.0 \\
\hline \multicolumn{5}{|l|}{ Employee classification } \\
\hline Executive & 0.0 & $0.1[0.0-18.0]$ & 0.0 & 0.0 \\
\hline Professional staff & 14.7 & $0.7[0.2-3.2]$ & 17.6 & $3.2[0.5-18.9]$ \\
\hline Classified staff & 21.6 & $0.7[0.1-4.1]$ & 16.5 & $4.7[0.7-29.7]$ \\
\hline Faculty & 0.0 & $0.3[0.0-2.8]$ & 3.6 & 0.0 \\
\hline Adjunct faculty & 10.0 & 1.0 & 20.0 & 1.0 \\
\hline \multicolumn{5}{|l|}{ Physical activity level } \\
\hline Active & 10.8 & $0.1[0.0-0.5]$ & 7.6 & $0.5[0.1-2.4]$ \\
\hline Irregular & 16.3 & $0.3[0.1-1.0]$ & 19.0 & $0.7[0.2-3.0]$ \\
\hline Inactive & 19.0 & 1.0 & 38.1 & 1.0 \\
\hline \multicolumn{5}{|l|}{ BMI } \\
\hline $\begin{array}{l}\text { Underweight or } \\
\text { normal }[<25]\end{array}$ & 13.3 & $0.5[0.2-1.3]$ & 7.5 & $1.5[0.5-4.0]$ \\
\hline Overweight [25-29.9] & 14.5 & $0.6[0.3-1.3]$ & 14.4 & $1.2[0.5-2.9]$ \\
\hline Obese $[\geq 30]$ & 12.7 & 1.0 & 24.5 & 1.0 \\
\hline
\end{tabular}




\begin{tabular}{lcccccc}
\hline & \multicolumn{2}{c}{ Current injury or ill-health } & & \multicolumn{2}{c}{ Support of supervisor } \\
\cline { 2 - 3 } \cline { 5 - 6 } Characteristic & $\%$ & OR $[95 \% \mathrm{CI}]$ & & $\%$ & OR [95\% CI] \\
\hline Wellness program & 10.9 & $1.6[0.7-3.7]$ & & 15.0 & $0.4[0.2-0.9]$ \\
$\quad$ Participant & 17.3 & 1.0 & & 14.5 & 1.0 \\
$\quad$ Non-participant & $14.8^{*}$ & & & $13.6^{* *}$ & \\
Total & & & & & & \\
\hline
\end{tabular}

Note. $\mathrm{OR}=$ odds ratio; $\mathrm{CI}=$ confidence interval. Respondents selected a yes response for as many barriers they felt keep or would keep them from participating in a free employee wellness program. $p$ Values are for Hosmer-Lemeshow goodness-of-fit test, where, at $\alpha=.05$, a $p$ value greater than .05 describes a significant fit of the model to the model data. Statistically significant odds ratios (CI does not include a 1.0) are depicted by bold typeface.

${ }^{a}$ Weighted percentages and data used in calculating odds ratios were adjusted to 2008 gender and employee classification statistics of Weber State University.

$* p=0.010$

$* * p=0.786$

to report lack of energy (OR, 5.1; 95\% CI, 1.4-18.4; OR, 196800000.0; 95\% CI, ;OR, 4.5; 95\% CI, 1.7-11.9). Adjunct faculty were the least likely to report no time during the work day, and lack of self-discipline (OR, 1.0; OR, 1.0). Inactive respondents were least likely to report no interest, no time during work day, and already involved in other programs. Inactive respondents, however, were most likely to report lack of energy, and current injury or ill-health. Underweight and overweight respondents were less likely to report lack of energy (OR, 0.2; 95\% CI, 0.1-0.6; OR, 0.4; 95\% CI, 0.2-0.9) than obese respondents. Results did not vary by whether employees were current wellness program participants or not.

\section{Selected Incentives to Wellness Services}

The most commonly reported incentives for utilizing employee wellness services or policies were having programs held at a convenient time (66.6\%), paid time off work 
to attend (64.2\%), and having programs held at a convenient location (53.9\%) (Table 7). Women were 2 times more likely to report having programs held at a convenient time. Respondents 18-34 years were 3 times more likely to report being able to invite family members or friends than respondents 60 or more years; while all ages 59 and under were 2-11 times more likely to report paid time off to attend. College graduates and respondents with master's degrees (as their highest degree) were least likely to report having good coworker participation. Respondents who were underweight or normal were more likely than respondents who were obese to report good coworker participation (OR, $2.4 ; 95 \%$ CI, 1.2-4.8) as incentive to participate. Results did not vary by physical activity level or by whether or not respondents were a current wellness program participant. 
Table 7

Selected Incentives to Wellness Services Among Benefits-Eligible Employees

\begin{tabular}{|c|c|c|c|c|}
\hline \multirow[b]{2}{*}{ Characteristic } & \multicolumn{2}{|c|}{$\begin{array}{l}\text { Encouragement from } \\
\text { supervisor }\end{array}$} & \multicolumn{2}{|c|}{ Paid time off work to attend } \\
\hline & $\%$ & OR $[95 \% \mathrm{CI}]$ & $\%$ & OR $[95 \% \mathrm{CI}]$ \\
\hline \multicolumn{5}{|l|}{ Sex } \\
\hline Female & 43.2 & $0.8[0.4-1.4]$ & 69.9 & $1.1[0.6-2.0]$ \\
\hline Male & 40.5 & 1.0 & 54.8 & 1.0 \\
\hline \multicolumn{5}{|l|}{ Age (years) } \\
\hline $18-29$ & 55.6 & $2.8[1.0-7.7]$ & 90.9 & $10.8[2.9-40.1]$ \\
\hline $30-34$ & 54.8 & $2.7[1.0-7.3]$ & 76.2 & $4.2[1.5-11.7]$ \\
\hline $35-44$ & 45.8 & $2.1[0.9-5.3]$ & 63.9 & $3.1[1.3-7.4]$ \\
\hline $45-59$ & 35.2 & $1.3[0.6-2.9]$ & 59.8 & $2.2[1.0-4.8]$ \\
\hline 60 or more & 31.4 & 1.0 & 43.1 & 1.0 \\
\hline \multicolumn{5}{|l|}{ Education } \\
\hline $\begin{array}{l}\text { High school } \\
\text { diploma or less }\end{array}$ & 60.0 & 1.0 & 80.0 & 1.0 \\
\hline Some college & 48.5 & $0.2[0.0-2.0]$ & 77.9 & $0.4[0.0-5.0]$ \\
\hline College graduate & 46.5 & $0.2[0.0-1.7]$ & 70.9 & $0.3[0.0-3.4]$ \\
\hline Masters degree & 44.3 & $0.4[0.0-3.0]$ & 59.5 & $0.4[0.0-4.7]$ \\
\hline Doctorate degree & 17.0 & $0.2[0.0-1.8]$ & 34.6 & $0.3[0.0-3.2]$ \\
\hline \multicolumn{5}{|l|}{ Employee classification } \\
\hline Executive & 22.2 & $0.8[0.1-7.5]$ & 37.5 & $0.9[0.1-5.8]$ \\
\hline Professional staff & 55.1 & $3.1[0.9-10.2]$ & 69.9 & $2.7[0.8-8.9]$ \\
\hline Classified staff & 47.1 & $2.9[0.8-10.9]$ & 78.6 & $4.6[1.2-17.6]$ \\
\hline Faculty & 14.5 & $0.6[0.1-2.4]$ & 30.9 & $0.7[0.2-2.5]$ \\
\hline Adjunct faculty & 23.3 & 1.0 & 56.7 & 1.0 \\
\hline \multicolumn{5}{|l|}{ Physical activity level } \\
\hline Active & 38.2 & $0.6[0.2-1.8]$ & 62.7 & $1.3[0.4-3.9]$ \\
\hline Irregular & 45.8 & $0.9[0.3-2.6]$ & 66.7 & $1.1[0.4-3.3]$ \\
\hline Inactive & 42.9 & 1.0 & 57.1 & 1.0 \\
\hline \multicolumn{5}{|l|}{ BMI } \\
\hline $\begin{array}{l}\text { Underweight or } \\
\text { normal }[<25]\end{array}$ & 42.5 & $1.2[0.6-2.3]$ & 66.4 & $1.5[0.7-3.0]$ \\
\hline Overweight [25-29.9] & 38.2 & $0.7[0.4-1.4]$ & 64.5 & $1.4[0.7-2.7]$ \\
\hline
\end{tabular}




\begin{tabular}{|c|c|c|c|c|}
\hline \multirow[b]{2}{*}{ Characteristic } & \multicolumn{2}{|c|}{$\begin{array}{l}\text { Encouragement from } \\
\text { supervisor }\end{array}$} & \multicolumn{2}{|c|}{ Paid time off work to attend } \\
\hline & $\%$ & OR $[95 \% \mathrm{CI}]$ & $\%$ & OR $[95 \% \mathrm{CI}]$ \\
\hline Obese $[\geq 30]$ & 46.1 & 1.0 & 61.4 & 1.0 \\
\hline \multicolumn{5}{|l|}{ Wellness program } \\
\hline Participant & 49.2 & $1.8[1.0-3.2]$ & 65.3 & $0.8[0.5-1.5]$ \\
\hline Non-participant & 32.4 & 1.0 & 62.6 & 1.0 \\
\hline Total & $42.2^{*}$ & & $64.2^{* *}$ & \\
\hline
\end{tabular}

Note. $\mathrm{OR}=$ odds ratio; $\mathrm{CI}=$ confidence interval. Respondents selected a yes response for as many incentives they felt make or would make them interested in participating in a free employee wellness program. $p$ Values are for Hosmer-Lemeshow goodness-of-fit test, where, at $\alpha=.05$, a $p$ value greater than .05 describes a significant fit of the model to the model data. Statistically significant odds ratios (CI does not include a 1.0) are depicted by bold typeface.

${ }^{a}$ Weighted percentages and data used in calculating odds ratios were adjusted to 2008 gender and employee classification statistics of Weber State University.

$* p=0.008$

$* * p=0.886$

(table continues) 


\begin{tabular}{|c|c|c|c|c|}
\hline \multirow[b]{2}{*}{ Characteristic } & \multicolumn{2}{|c|}{$\begin{array}{l}\text { Having programs held at a } \\
\text { convenient time }\end{array}$} & \multicolumn{2}{|c|}{$\begin{array}{l}\text { Having programs held at a } \\
\text { convenient location }\end{array}$} \\
\hline & $\%$ & OR $[95 \% \mathrm{CI}]$ & $\%$ & OR $[95 \% \mathrm{CI}]$ \\
\hline \multicolumn{5}{|l|}{ Sex } \\
\hline Female & 72.8 & $2.2[1.2-4.0]$ & 60.7 & $1.5[0.9-2.7]$ \\
\hline Male & 56.3 & 1.0 & 42.9 & 1.0 \\
\hline \multicolumn{5}{|l|}{ Age (years) } \\
\hline $18-29$ & 68.2 & $1.4[0.5-3.9]$ & 54.5 & $1.2[0.5-3.1]$ \\
\hline $30-34$ & 76.2 & $1.8[0.7-4.8]$ & 66.7 & $2.1[0.8-5.5]$ \\
\hline $35-44$ & 69.4 & $1.6[0.7-3.8]$ & 58.3 & $1.6[0.7-3.8$ \\
\hline $45-59$ & 63.1 & $1.1[0.5-2.3]$ & 49.2 & $1.0[0.5-2.2]$ \\
\hline 60 or more & 60.8 & 1.0 & 47.1 & 1.0 \\
\hline \multicolumn{5}{|l|}{ Education } \\
\hline $\begin{array}{l}\text { High school } \\
\text { diploma or less }\end{array}$ & 80.0 & 1.0 & 20.0 & 1.0 \\
\hline Some college & 67.2 & $0.3[0.0-3.2]$ & 57.4 & $3.1[0.3-37.7]$ \\
\hline College graduate & 64.3 & $0.4[0.0-4.2]$ & 52.4 & $3.9[0.3-47.5]$ \\
\hline Masters degree & 75.9 & $0.6[0.1-7.7]$ & 67.1 & $11.1[0.9-141.4]$ \\
\hline Doctorate degree & 56.6 & $0.4[0.0-4.5]$ & 37.7 & $7.6[0.6-104.0]$ \\
\hline \multicolumn{5}{|l|}{ Employee classification } \\
\hline Executive & 37.5 & $0.5[0.1-3.6]$ & 37.5 & $0.3[0.5-2.0]$ \\
\hline Professional staff & 64.0 & $1.2[0.4-3.8]$ & 53.7 & $0.6[0.2-2.0]$ \\
\hline Classified staff & 69.6 & $1.4[0.4-4.9]$ & 61.2 & $1.2[0.3-4.2]$ \\
\hline Faculty & 67.3 & $1.8[0.5-6.8]$ & 32.7 & $0.2[0.1-0.8]$ \\
\hline Adjunct faculty & 73.3 & 1.0 & 73.3 & 1.0 \\
\hline \multicolumn{5}{|l|}{ Physical activity level } \\
\hline Active & 62.4 & $1.2[0.4-3.6]$ & 52.2 & $1.0[0.3-2.9]$ \\
\hline Irregular & 71.9 & $1.8[0.6-5.3]$ & 56.2 & $1.2[0.4-3.3]$ \\
\hline Inactive & 57.1 & 1.0 & 50.0 & 1.0 \\
\hline \multicolumn{5}{|l|}{ BMI } \\
\hline $\begin{array}{l}\text { Underweight or } \\
\text { normal }[<25]\end{array}$ & 62.2 & $0.8[0.4-1.6]$ & 50.0 & $0.8[0.4-1.5]$ \\
\hline Overweight [25-29.9] & 71.8 & $1.7[0.9-3.4]$ & 55.5 & $1.1[0.6-2.1]$ \\
\hline Obese $[\geq 30]$ & 66.3 & 1.0 & 56.9 & 1.0 \\
\hline
\end{tabular}




\begin{tabular}{lcccccc}
\hline & \multicolumn{2}{c}{$\begin{array}{c}\text { Having programs held at a } \\
\text { convenient time }\end{array}$} & & \multicolumn{2}{c}{$\begin{array}{c}\text { Having programs held at a } \\
\text { convenient location }\end{array}$} \\
\cline { 2 - 3 } \cline { 5 - 7 } Characteristic & $\%$ & OR $[95 \% \mathrm{CI}]$ & & $\%$ & OR [95\% CI] \\
\hline Wellness program & 65.3 & $0.8[0.4-1.4]$ & & 54.9 & $1.0[0.6-1.7]$ \\
Participant & 68.1 & 1.0 & & 52.5 & 1.0 \\
$\quad$ Non-participant & $66.6^{*}$ & & & $53.9^{* *}$ & \\
Total & & & & & & \\
\hline
\end{tabular}

Note. $\mathrm{OR}=$ odds ratio; $\mathrm{CI}=$ confidence interval. Respondents selected a yes response for as many incentives they felt make or would make them interested in participating in a free employee wellness program. $p$ Values are for Hosmer-Lemeshow goodness-of-fit test, where, at $\alpha=.05$, a $p$ value greater than .05 describes a significant fit of the model to the model data. Statistically significant odds ratios (CI does not include a 1.0) are depicted by bold typeface.

${ }^{a}$ Weighted percentages and data used in calculating odds ratios were adjusted to 2008 gender and employee classification statistics of Weber State University.

$* p=0.668$

$* * p=0.659$

(table continues) 


\begin{tabular}{|c|c|c|c|c|}
\hline \multirow[b]{2}{*}{ Characteristic } & \multicolumn{2}{|c|}{$\begin{array}{l}\text { Having good coworker } \\
\text { participation }\end{array}$} & \multicolumn{2}{|c|}{$\begin{array}{l}\text { Being able to invite family } \\
\text { members or friends }\end{array}$} \\
\hline & $\%$ & OR $[95 \% \mathrm{CI}]$ & $\%$ & OR $[95 \% \mathrm{CI}]$ \\
\hline \multicolumn{5}{|l|}{ Sex } \\
\hline Female & 34.0 & $0.8[0.5-1.5]$ & 42.7 & $0.9[0.5-1.5]$ \\
\hline Male & 36.8 & 1.0 & 36.5 & 1.0 \\
\hline \multicolumn{5}{|l|}{ Age (years) } \\
\hline $18-29$ & 43.2 & $1.6[0.6-4.2]$ & 47.7 & $2.5[0.9-6.6]$ \\
\hline $30-34$ & 42.9 & $1.6[0.6-4.1]$ & 47.6 & $2.8[1.1-7.3]$ \\
\hline $35-44$ & 34.7 & $1.6[0.7-3.9]$ & 46.6 & $3.4[1.4-8.3]$ \\
\hline $45-59$ & 30.3 & $0.9[0.4-1.9]$ & 39.3 & $2.2[1.0-4.8]$ \\
\hline 60 or more & 32.7 & 1.0 & 21.6 & 1.0 \\
\hline \multicolumn{5}{|l|}{ Education } \\
\hline $\begin{array}{l}\text { High school } \\
\text { diploma or less }\end{array}$ & 80.0 & 1.0 & 20.0 & 1.0 \\
\hline Some college & 51.5 & $0.2[0.0-2.5]$ & 47.1 & $3.2[0.3-35.6]$ \\
\hline College graduate & 33.1 & $0.1[0.0-0.9]$ & 40.2 & $2.6[0.2-29.3]$ \\
\hline Masters degree & 26.6 & $0.1[0.0-0.8]$ & 44.3 & $4.5[0.4-52.3]$ \\
\hline Doctorate degree & 26.9 & $0.1[0.0-1.3]$ & 28.8 & $3.3[0.3-40.0]$ \\
\hline \multicolumn{5}{|l|}{ Employee classification } \\
\hline Executive & 25.0 & $1.0[1.1-9.8]$ & 25.0 & $0.3[0.0-2.6]$ \\
\hline Professional staff & 40.4 & $3.1[0.8-11.7]$ & 42.6 & $1.0[0.4-3.0]$ \\
\hline Classified staff & 40.2 & $2.3[0.5-9.7]$ & 44.7 & $1.5[0.5-4.9]$ \\
\hline Faculty & 25.5 & $1.4[0.3-6.4]$ & 25.5 & $0.4[0.1-1.5]$ \\
\hline Adjunct faculty & 13.3 & 1.0 & 46.7 & 1.0 \\
\hline \multicolumn{5}{|l|}{ Physical activity level } \\
\hline Active & 34.8 & $1.1[0.3-3.8]$ & 38.9 & $0.7[0.2-1.9]$ \\
\hline Irregular & 36.6 & $1.2[0.4-3.8]$ & 41.6 & $0.8[0.3-2.3]$ \\
\hline Inactive & 23.8 & 1.0 & 42.9 & 1.0 \\
\hline \multicolumn{5}{|l|}{ BMI } \\
\hline $\begin{array}{l}\text { Underweight or } \\
\text { normal }[<25]\end{array}$ & 41.7 & $2.4[1.2-4.8]$ & 44.5 & $1.8[1.0-3.5]$ \\
\hline Overweight [25-29.9] & 34.2 & $1.6[0.8-3.0]$ & 38.7 & $1.2[0.7-2.3]$ \\
\hline Obese $[\geq 30]$ & 28.4 & 1.0 & 37.3 & 1.0 \\
\hline
\end{tabular}




\begin{tabular}{|c|c|c|c|c|}
\hline \multirow[b]{2}{*}{ Characteristic } & \multicolumn{2}{|c|}{$\begin{array}{l}\text { Having good coworker } \\
\text { participation }\end{array}$} & \multicolumn{2}{|c|}{$\begin{array}{l}\text { Being able to invite family } \\
\text { members or friends }\end{array}$} \\
\hline & $\%$ & OR $[95 \% \mathrm{CI}]$ & $\%$ & OR $[95 \% \mathrm{CI}]$ \\
\hline \multicolumn{5}{|l|}{ Wellness program } \\
\hline Participant & 39.9 & $1.4[0.8-2.5]$ & 41.8 & $1.2[0.7-2.1]$ \\
\hline Non-participant & 28.3 & 1.0 & 38.4 & 1.0 \\
\hline Total & $34.9^{*}$ & & $40.4^{* *}$ & \\
\hline
\end{tabular}

Note. $\mathrm{OR}=$ odds ratio $\mathrm{CI}=$ confidence interval. Respondents selected a yes response for as many incentives they felt make or would make them interested in participating in a free employee wellness program. $p$ Values are for Hosmer-Lemeshow goodness-of-fit test, where, at $\alpha=.05$, a $p$ value greater than .05 describes a significant fit of the model to the model data. Statistically significant odds ratios (CI does not include a 1.0) are depicted by bold typeface.

${ }^{a}$ Weighted percentages and data used in calculating odds ratios were adjusted to 2008 gender and employee classification statistics of Weber State University.

$* p=0.516$

$* * p=0.492$ 


\section{CHAPTER V \\ DISCUSSION}

Comprehensive WHP programs are progressively becoming an effective and efficient way to foster behavior change, improve the bottom line of businesses, and lower overall health care costs (Aldana, 2001; Chapman, 2005; Goetzel \& Ozminkowski, 2008). Although the evidence of these benefits is vast, reported participation rates are far from what many feel would yield considerably greater benefits. One strategy suggested to improving participation and the effectiveness of these programs is evaluating the perceived barriers and incentives to participation. There are few data on programs that have done this; therefore, the purpose of this study was to determine the perceived barriers and incentives to participation in an existing comprehensive employee wellness program at Weber State University.

The findings of this study suggest that $75.9 \%$ of employees perceived they would use an available fitness center. Health screening tests would reportedly be used by $75.6 \%$ of employees, and $69.6 \%$ of employees perceived paid time to exercise at work as a WHP policy that would encourage them to exercise. Diet or exercise counseling and onsite exercise classes were perceived by $57.5 \%$ and $53.0 \%$, respectively, also as policies that would encourage employees to exercise, as well eat a healthier diet.

Although $64.2 \%$ of respondents selected paid time off to attend wellness services (second highest selected incentive), allowing for such a policy may not be feasible for an employer. Additional research concerning the ROI of this specific policy, as well as whether or not respondents that say they would participate in this policy actually 
participate needs to be done. Possible benefits of the policy of paid time off work to attend wellness services are decreases in overall illnesses, increases in overall health, prevention of future chronic health problems, attracting and retaining employees through increased employee morale, and ultimately, an increase in employee productivity (Chapman, 2005; Peters, 1997). Improvements in employee productivity are hoped to more than compensate for the employer-paid hours away from work in order to participate in wellness services. Paid time off work to attend may also help employees overcome certain other perceived barriers, such as no time during the workday, which was overwhelmingly the most frequently reported perceived barrier $(60.2 \%)$ in this study.

It was interesting to note that the only statistically significant perceived barrier to participation between current wellness participants and non-participants was having the current support of their supervisor. Employees who were current participants of the wellness program were less than half as likely to report current support of supervisor as a barrier to participation (OR, 0.4; CI 95\%, 0.2-0.9). Although the most frequent reported barrier to participation was no time during the workday, the only barrier significantly different between employees that were already participating and employees that did not participate was current support of supervisor. Although the employer in this study was already willing to implement paid time off work to exercise, allowing the policy of paid time off work to exercise was ultimately at the discretion of each employee's direct supervisor. The results of this study show there may be a large number of supervisors that are less willing to support this policy. Focusing greater efforts on convincing supervisors of the benefits the wellness program may directly have on them and their 
respective departments may help a substantial number of employees overcome this barrier and begin participating in the wellness services being offered. This, and other institutionalized barriers may be overcome by utilizing input from more diverse and equally representative focus groups from within the university in the process of planning services and policies of a university-based wellness program (Reger et al., 2002). For example, including supervisors in the planning and development of wellness services and policies may increase their accountability for program success. Such a strategy may increase supervisor's likelihood to allow employee paid time off work to participate in wellness services.

Employers may benefit from the results of this study combined with their own internal assessment of employee barriers and incentives to participation. Employees are more likely to participate in wellness services when the services are considered attractive. A reasonable approach to making interventions more attractive is collecting employee input. Many of the wellness services and policies inquired of the employees in this study were already being offered as free benefits at the time this study was realized. This may also be the case with many other employers where inquiring employees perceived barriers and incentives to wellness services. Regardless of what wellness services are or are not currently offered to employees, it may be valuable to assess whether the services already being offered are considered attractive and helpful to the potential participants.

It's been strongly suggested that effective efforts to increase participation in employers' WHP programs require utilizing theoretical health behavior models. Health promotion interventions that have followed the constructs of the Transtheoretical model 
of health behavior, in particular, have been successful with treating diabetes, increasing exercise and fruit and vegetable consumption, improving overall diet, smoking cessation, and preventive health screening adherence, to name a few (Glanz et al., 2008). Implementing stage-based health behavior models involves first determining the current health behavior stages of change among eligible participants. This can be done by identifying the current barriers and incentives to WHP participation during the development and/or improvement of a WHP program. Reducing the most costly risks in any population involves reaching the right individuals with the right interventions and at a time when they are ready to modify their health behaviors (Glanz et al., 2008; Prochaska \& Velicer, 1997).

Valuable input was gained from this study by stratifying employee responses to their different demographic characteristics. For example, the more education reported by employees, the more they reported being already involved in other programs or activities, as well as current injury or poor health as barriers to participating in their employers' wellness program. A similar trend of these same barriers was also seen when stratifying respondents by employee classification. This could be because employees with greater education may have been the same employees with the higher classifications of employment. Similar categorical trends were observed in the responses of selected incentives to participation. An additional demographical trend was observed between the age of respondents and their likelihood to report paid time off to attend, encouragement from supervisor, and being able to invite family members or friends as incentives to participation. The younger the respondent, the more likely he or she was to report each 
of these incentives. There may be a relationship with both the age and classification of employees and whether they are salary or hourly-paid employees. Paid time off work to exercise is less applicable to employees paid by salary than employees paid hourly.

Because there are little published data on employee perceived barriers and incentives to participation in employer sponsored WHP services and policies, few comparisons can be made with the stratified responses of this study and responses of others. The results of Kruger, Yore, Bauer, and Kohl (2007) also revealed an observational trend with the age of respondents and their likelihood to be incentivized by employee encouragement, employer time paid off, and ability to invite family members and friends. Having programs held at a convenient time and location, and paid time off work to attend were the most frequently reported incentives in both this study and that of Kruger et al. Many demographic characteristics reported by Kruger et al. were also very similar to the demographics reported in this study, including the age of respondents, physical activity levels, and BMI.

The greatest benefit of this study may be discovering the services, policies, and barriers attributed specifically to the employees that reported multiple health risks, such as physical inactivity, BMI, and age. Because individuals with multiple health risks generally accumulate greater health care costs (Andrews, 2001; Goetzel et al., 1998, 2003), developing WHP services based on the needs of individuals with multiple health risks may yield the most considerable cost savings. Developing WHP services and programs based on the needs of employees with multiple health risks should not, however, undermine the importance of making programs attractive to employees with 
low health risks. In the long term, it is equally important to make programs attractive to these employees in order to help keep them healthy.

Results of this study were subject to multiple limitations. First, the results of this study are based on self-report data of volunteered participants. Responses of this study are most reliable only when making generalizations to those who chose to respond to the questionnaire. The opinions of employees who chose not to respond to the questionnaire may be different than the opinions of the employees who did respond. Although the results of this study were weighted to the level of education and the gender of the employees at this university, participants in this study may still be different from the other employees of the accessible employee population. Second, the questionnaire asked respondents to select barriers, incentives, and perceived use only of the services listed on the questionnaire. There was not a "none" response, which may have compelled respondents to make a selection not strongly felt for. Third, data are cross-sectional and assume the preferences, incentives, and barriers of respondents do not change over time. Fourth, the time at which the questionnaire was administered and made available to eligible wellness participants was during the early months of the summer, which is between the busiest school semesters (fall and spring). Many faculty and staff may not have been available at this time with equal opportunity to respond to the questionnaire. This may have been the leading cause of the low response rate of this survey. This may also have been a large reason why the majority of respondents were female. The majority of female respondents were also classified and professional staff, who are more 
commonly paid hourly, and therefore more traditionally present at work during the time of year the questionnaire was administered (summer).

This study is unique because it attempted to describe perceived barriers and incentives to participation in WHP services and polices. There are few published data on the perceived needs of employees. The results of this study were taken from a large sample of a large employer and generalizations to other worksites, settings, and demographics should be made with caution. Combined with the results of the most recent survey of perceived employee needs by Kruger, and colleagues (2007), the results of this study appear reliable to the demographics by which they were stratified. Nonetheless, much more research is needed to determine the perceived needs of employees in a variety of work settings and demographics. For example, determining the needs of employees at greatest risk for disease and high health care costs may have the most pronounced effect on health care savings through WHP interventions. In order to determine if offering employees paid time off work to exercise, or participate in other WHP services, more longitudinal studies would need to be done. Employee changes in health care costs, work productivity, absenteeism, and other behaviors associated with individual health need to be tracked and determined if, as a result of employee paid time off work to exercise, their savings attributed to exercising at work are greater than the costs of allowing the paid time off work to do so. There may also be certain amounts of time allowed to exercise at work that are more optimal in terms of ROI than others. For example, allowing four hours per week off work to exercise may have a greater ROI than offering $6 \mathrm{hr}$. Group controlled and more structured exercise time may further improve 
the use of time away from work for exercise. Each of these suggestions needs to be looked at in order to use most effectively use the information found in this study. Because lack of time was also a leading reported barrier to WHP participation in this study, examining the feasibility of offering paid time off work to exercise may be the most valuable next step to take in improving WHP participation.

The results of this study, combined with the results of an employer's own internal assessment of their employee population, can have a profound effect on the development of WHP programs that attract and retain employee participation. The most commonly reported barrier to wellness program participation in this study was no time during workday, while the most commonly reported incentives were having programs held at a convenient time, paid time off work to attend, and having programs held at a convenient location. Designing WHP programs based on these and their own assessment of perceived needs, will allow employers to better support behavior change, help control health care costs, and improve their financial bottom line. 


\section{REFERENCES}

Aldana, S. G. (2001). Financial impact of health promotion programs: a comprehensive review of the literature. American Journal of Health Promotion, 15, 296-320.

Anderson, D. R., Whitmer, R. W., Goetzel, R. Z., Ozminkowski, R. J., Dunn, R. L., Wasserman, J., et al. (2000). The relationship between modifiable health risks and group-level health care expenditures. American Journal of Health Promotion, $15,45-52$.

Andrews, B. (2001). The relationship between modifiable health risks and group-level health care expenditures. Journal of Allied Health, 30, 201-202.

Arias, E. (2007). United States life tables, 2004. National Vital Statistics Reports: From the CentersfFor Disease Control and Prevention, National Center for Health Statistics, National Vital Statistics System, 56, 1-39.

Barker, J. W., \& Glass, J. C., Jr. (1990). Perceived wellness needs of university employees. Journal of American College Health, 38(4), 187-189.

Belcher, O. A. (1990). Survey of employee health promotion programs in public research and doctorate-granting institutions in the United States with comparisons to the National Survey of Worksite Health Promotion activities (Doctoral dissertation, University of Alabama, 1990). Dissertation Abstracts International, 51,1452 .

Bridle, C., Riemsma, R. P., Pattenden, J., Sowden, A. J., Mather, L., Watt, I. S., et al. (2005). Systematic review of the effectiveness of health behavior interventions based on the transtheoretical model. Psychology \& Health, 20, 283-301.

Brown, S. (2005). Measuring perceived benefits and perceived barriers for physical activity. American Journal of Health Behavior, 29, 107-116.

Bruce, G. M. (1993). Implementing a university campus wellness model. $A A O H N$ Journal: Official Journal of The American Association of Occupational Health Nurses, 41, 120-123.

Bull, A. J., Eckerson, J. M. F., Moore, G. A., Pfeifer, P. C., \& Obermiller, D. R. (2006). Employee perceptions of wellness program needs at a midwestern university. Medicine \& Science in Sports \& Exercise, 38 (Suppl.), S253.

Burton, W., Chen, C., Conti, D., Schultz, A., Pransky, G., \& Edington, D. (2005). The association of health risks with on-the-job productivity. Journal of Occupational and Environmental Medicine, 47, 769-777. 
Busbin, J. W., \& Campbell, D. P. (1990). Employee wellness programs: A strategy for increasing participation. Journal of Health Care Marketing, 10, 22-30.

Chapman, L. S. (2005). Meta-evaluation of worksite health promotion economic return studies: 2005 update. American Journal of Health Promotion, 19, 1-10.

Chenoweth, D. H. (1999). Worksite health promotion. American Fitness, 17, 43.

Chenoweth, D., \& Leutzinger, J. (2006). The Economic Cost of Physical Inactivity and Excess Weight in American Adults. Journal of Physical Activity \& Health, 3:148-163.

Cox, C. (2003). ACSM's worksite health promotion manual: a guide to building and sustaining healthy worksites. Champaign, IL: Human Kinetics.

Crump, C. E., Earp, J. A. L., Kozma, C. M., \& Hertz-Picciotto, I. (1996). Effect of organization-level variables on differential employee participation in 10 federal worksite health promotion programs. Health Education Behavior, 23, 204-223.

Crump, C. E., Shegog, R., Gottlieb, N. H., \& Grunbaum, J. A. (2001). Comparison of participation in federal worksite and community health promotion programs. American Journal of Health Promotion, 15, 232-236.

Davis, K. E., Jackson, K. L., Kronenfeld, J. J., \& Blair, S. N. (1984). Intent to participate in worksite health promotion activities: a model of risk factors and psychosocial variables. Health Education \& Behavior, 11, 361.

Department of Health and Human Services. (2000). Healthy People 2010: understanding and improving health. Retrieved from http://www.healthypeople.gov/Document/HTML/Volume2/19Nutrition.htm\#_To c490383126

Department of Health and Human Services. (2003). Prevention makes common "cents". Retrieved November 20, 2008 from http://aspe.hhs.gov/health/prevention/.

Donato, K. A. (1998). Executive summary of the clinical guidelines on the identification, evaluation, and treatment of overweight and obesity in adults. Archives of Internal Medicine, 158, 1855-1867.

Eckhart, G. A., Ebro, L. L., \& Claypool, P. L. (1988). Needs, interests, and attitudes of university faculty for a wellness program. Journal of the American Dietetic Association, 88, 916-920.

Finkelstein, E., Fiebelkorn, I., \& Wang, G. (2003). National medical spending attributable to overweight and obesity: how much, and who's paying. Health Affairs, 3, 219-226. 
Finkelstein, E., Fiebelkorn, I. C., \& Wang, G. (2005). The costs of obesity among fulltime employees. American Journal Of Health Promotion: AJHP, 20, 45-51.

Finkelstein, E. A., Ruhm, C. J., \& Kosa, K. M. (2005). Economic causes and consequences of obesity. Annual Review of Public Health, 26, 239-257.

Flegal, K. M., Carroll, M. D., Ogden, C. L., \& Johnson, C. L. (2002). Prevalence and trends in obesity among US adults, 1999-2000. JAMA: The Journal of the American Medical Association, 288, 1723-1727.

Gilmour, D. J. (1993). An analysis of needs and perceived barriers related to implementation of health promotion programs in Pennsylvania community colleges (faculty health). Dissertation Abstracts International, 54(07A), 169.

Glanz, K., Rimer, B., \& Viswanath, K. (2008). Health behavior and health education: Theory, research, and practice (4th ed.). San Francisco: Wiley.

Glasgow, R. E., Lichtenstein, E., \& Marcus, A. C. (2003). Why don't we see more translation of health promotion research to practice? Rethinking the efficacy-toeffectiveness transition. American Journal of Public Health, 93, 1261-1267.

Glasgow, R. E., McCaul, K. D., \& Fisher, K. J. (1993). Participation in worksite health promotion: A critique of the literature and recommendations for future practice. Health Education Quarterly, 20, 391-408.

Goetzel, R., Anderson, D., Whitmer, R., Ozminkowski, R., Dunn, R., \& Wasserman, J. (1998). The relationship between modifiable health risks and health care expenditures: An analysis of the multi-employer HERO health risk and cost database. Journal of Occupational and Environmental Medicine, 40, 843.

Goetzel, R., Guindon, A., Turshen, J., \& Ozminkowski, R. (2001). Health and productivity management: Establishing key performance measures, benchmarks, and best practices. Journal of Occupational \& Environmental Medicine, 43, 1017.

Goetzel, R., Hawkins, K., Ozminkowski, R. J., \& Wang, S. (2003). The health and productivity cost burden of the "top 10" physical and mental health conditions affecting six large U.S. employers in 1999. Journal of Occupational and Environmental Medicine / American College of Occupational and Environmental Medicine, 45, 5-14.

Goetzel, R. Z., Long, S. R., Ozminkowski, R. J., Hawkins, K., Wang, S., \& Lynch, W. (2004). Health, absence, disability, and presenteeism cost estimates of certain physical and mental health conditions affecting U.S. employers. Journal of Occupational and Environmental Medicine / American College of Occupational and Environmental Medicine, 46, 398-412. 
Goetzel, R. Z., \& Ozminkowski, R. J. (2008). The health and cost benefits of work site health-promotion programs. Annual Review Of Public Health, 29, 303-323.

Goetzel, R. Z., Ozminkowski, R. J., Asciutto, A. J., Chouinard, P., \& Barrett, M. (2001). Survey of Koop award winners: Life-cycle insights. Art of Health Promotion, 5, $1-8$.

Goetzel, R. Z., \& Stewart, M. (2000). Pharmaceuticals--cost or investment? Journal of Occupational \& Environmental Medicine, 42, 338.

Greenberg, P. E., Finkelstein, S. N., \& Berndt, E. R. (1995). Economic consequences of illness in the workplace. Sloan Management Review, 36, 26.

Haines, D. J., Davis, L., Rancour, P., Robinson, M., Neel-Wilson, T., \& Wagner, S. (2007). A pilot intervention to promote walking and wellness and to improve the health of college faculty and staff. Journal of American College Health, 55, 219225.

Harden, A., Peersman, G., Oliver, S., Mauthner, M., \& Oakley, A. (1999). A systematic review of the effectiveness of health promotion interventions in the workplace. Occupational Medicine (Oxford, England), 49, 540-548.

HealthStlyes syndicated survey data. (2004). Washington, DC: Porter Novelli.

Hollander, R. B., \& Lengermann, J. J. (1988). Corporate characteristics and worksite health promotion programs: Survey findings from Fortune 500 companies. Social Science \& Medicine (1982), 26, 491-501.

Hunt, M. K., Lederman, R., Potter, S., Stoddard, A., \& Sorensen, G. (2000). Results of employee involvement in planning and implementing the Treatwell 5-a-Day work-site study. Health Education \& Behavior, 27, 223-231.

Jaffee, L., Lutter, J. M., Rex, J., Hawkes, C., \& Bucaccio, P. (1999). Incentives and barriers to physical activity for working women. American Journal of Health Promotion, 13, 215.

Kaiser Family Foundation (2008, September 24). Employer health benefits: 2008 Annual survey: Henry J. Kaiser Family Foundation; Health Research, and Educational Trust. Retrieved February 26, 2009, from http://ehbs.kff.org/ pdf/7790.pdf

Kerner, J., Rimer, B., \& Emmons, K. (2005). Introduction to the special section on dissemination: dissemination research and research dissemination: how can we close the gap? Health Psychology, 24, 443-446.

Knapp, L. G., Kelly-Reid, J. E., Whitmore, R. W., Levine, B., Huh, S., \& Broyles, S. G. (2006). Employees in postsecondary institutions, Fall 2004, and salaries of full- 
time instructional faculty, 2004-05 (NCES 2006-187 ed.). U.S. Department of Education: National Center for Education Statistics.

Koretz, G. (2002). Employers tame medical costs: But workers pick up a bigger share. Business Week, 26, 26.

Kruger, J., Yore, M. M., Bauer, D. R., \& Kohl, H. W. (2007). Selected barriers and incentives for worksite health promotion services and policies. American Journal of Health Promotion, 21, 439-447.

Kwak, L., Kremers, S. P. J., van Baak, M. A., \& Brug, J. (2006). Participation rates in worksite-based intervention studies: health promotion context as a crucial quality criterion. Health Promotion International, 21, 66-69.

Lahtinen, E., Koskinen-Ollonqvist, P., Rouvinen-Wilenius, P., Tuominen, P., \& Mittelmark, M. B. (2005). The development of quality criteria for research: A Finnish approach. Health Promotion International, 20, 306-315.

Lassen, A., Bruselius-Jensen, M., Sommer, H. M., Thorsen, A. V., \& Trolle, E. (2007). Factors influencing participation rates and employees' attitudes toward promoting healthy eating at blue-collar worksites. Health Education Research, 22, 727-736.

Lerman, Y., \& Shemer, J. (1996). Epidemiologic characteristics of participants and nonparticipants in health-promotion programs. Journal of Occupational and Environmental Medicine, 38, 535.

Lewis, R. J., Huebner, W. W., \& Yarborough, C. M., 3rd. (1996). Characteristics of participants and nonparticipants in worksite health promotion. American Journal of Health Promotion, 11, 99-106.

Linnan, L. A., Sorensen, G., Colditz, G., Klar, D. N., \& Emmons, K. M. (2001). Using theory to understand the multiple determinants of low participation in worksite health promotion programs. Health Education \& Behavior, 28, 591-607.

Lippke, S., \& Ziegelmann, J. P. (2008). Theory-based health behavior change: Developing, testing, and applying theories for evidence-based interventions, Applied Psychology, 57, 698-716.

Lovato, C. Y., \& Green, L. W. (1990). Maintaining employee participation in workplace health promotion programs. Health Educcation \& Behavior, 17, 73-88.

Macera, C., Jones D., Yore M., Ham S., Kohl H., Kimsey C., \& Buchner, D. Prevalence of physical activity, including lifestyle activities among adults-United States, 2000-2001. Retrieved September 15, 2009 from http://www.cdc.gov/mmwr/preview/mmwrhtml/mm5232a2.htm. 
McGinnis, J. M., \& Foege, W. H. (1993). Actual causes of death in the United States. JAMA: The Journal of the American Medical Association, 270, 2207-2212.

Mokdad, A. H., Marks, J. S., Stroup, D. F., \& Gerberding, J. L. (2004). Actual causes of death in the United States, 2000. The Journal of the American Medical Association, 291, 1238-1245.

National Center for Health Statistics. (2009). Health, United States, 2008 with Chartbook. Hyattsville, MD: U.S. Department of Health and Human Services.

National Center for Health Statistics. (2008). Health, United States, 2007 with Chartbook. Hyattsville, MD: U.S. Department of Health and Human Services.

Noar, S.M., Benac C.N., and Harris, M.S. (2007). Does tailoring matter? Meta-analytic review of tailored print health behavior change interventions. Psychological Bulletin, 133,673-693.

Ogden, C. L., Carroll, M. D., Curtin, L. R., McDowell, M. A., Tabak, C. J., \& Flegal, K. M. (2006). Prevalence of overweight and obesity in the United States, 19992004. The Journal of the American Medical Association, 295, 1549-1555.

Pelletier, B., Boles, M., \& Lynch, W. (2004). Change in health risks and work productivity over time. Journal of Occupational and Environmental Medicine, 46, 746.

Peters, K. K. (1997). Worksite health promotion with campus maintenance workers. Dissertation Abstracts International, 58 (05B), 262.

Pi-Sunyer, F. X. (1993). Medical hazards of obesity. Annals of Internal Medicine, 119, 655-660.

Poisal, J. A., Truffer, C., Smith, S., Sisko, A., Cowan, C., Keehan, S., et al. (2007). Health spending projections through 2016: modest changes obscure part D's impact. Health Affairs, 26, w242-w253.

Prochaska, J.O., \& DiClemente C.C. (1983). Stages and processes of self-change of smoking: toward an integrative model of change. Journal of Consulting and Clinical Psychology, 51, 390-395.

Prochaska, J. O., \& Velicer, W. F. (1997). Behavior change: The Transtheoretical Model of health behavior change. American Journal of Health Promotion, 12, 38-48.

Reger, B., Williams, K., Kolar, M., Smith, H., \& Douglas, J. W. (2002). Implementing university-based wellness: A participatory planning approach. Health Promotion \& Practice, 3, 507-514. 
Resnicow, K., Davis, M., Smith, M., Baranowski, T., Lin, L. S., Baranowski, J., et al. (1998). Results of the TeachWell worksite wellness program. American Journal of Public Health, 88, 250-257.

Serxner, S., Anderson, D. R., \& Gold, D. (2004a). Building program participation: strategies for recruitment and retention in worksite health promotion programs. American Journal of Health Promotion, 18, 0-9.

Serxner, S., Anderson, D. R., \& Gold, D. (2004b). Building program participation: strategies for recruitment and retention in worksite health promotion programs. American Journal Of Health Promotion, 18, 1.

Shain, M., \& Kramer, D. M. (2004). Health promotion in the workplace: Framing the concept; reviewing the evidence. Occupational and Environmental Medicine, 61, 643-648.

Shephard, R. J. (1996). Worksite fitness and exercise programs: A review of methodology and health impact. American Journal of Health Promotion, 10, 436452.

Sloan, R. P., \& Gruman, J. C. (1988). Participation in workplace health promotion programs: The contribution of health and organizational factors. Health Education \& Behavior, 15, 269.

Sorensen, G., \& Barbeau, E. (2004). Steps to a healthier US workforce: integrating occupational health and safety and worksite health promotion: State of the science. Washington, DC: The National Institute of Occupational Safety and Health.

Sturm, R. (2002). The effects of obesity, smoking, and drinking on medical problems and costs. Health Affairs, 21, 245-253.

Thompson, D., Edelsberg, J., Kinsey, K. L., \& Oster, G. (1998). Estimated economic costs of obesity to U.S. business. American Journal Of Health Promotion, 13, $120-127$.

United States Census Bureau. (2006). American Community Survey. Washington, DC: U.S. Census Bureau.

Weber State University. (2008). Fast facts. Retrieved December 25, 2008, from http://www.weber.edu/AboutWSU/FastFacts.html

Weber State University Institutional Research. (2007). Retrieved December 25, 2008, from http://weber.edu/IR/faculty.html 
Williams, M. (1988). Health habits, perceived health status, and health interests of students and employees of a select university (Doctoral dissertation, Southern Illinois University at Carbondale, 1988). Dissertation Abstracts International, 50, 1956. 
APPENDICES 
Appendix A. Informed Consent Form 


\section{Informed Consent \\ Barriers and Incentives of WSU Wellness Program}

Trever Ball, WSU Staff in the Department of Health Promotion and Human Performance, and Professor Edward Heath of Utah State University, are conducting research to help determine barriers and incentives for use of the university's wellness program. We are requesting your participation to complete a short, five-question questionnaire. Time to complete the questionnaire should take approximately five to ten minutes. By participating in this study, you will provide valuable information regarding a portion of your benefits as an employee of Weber State University.

In order to provide you with the greatest amount of confidentiality, the responses to your questionnaire will instantaneously and anonymously be added to a secure electronic database stored on WSU's computer servers accessible only by the researchers of this study. Please be aware that your responses will be used for the purposes of this study alone. Demographic information collected (gender, age, ethnicity, etc.) will be used only to determine differences between responses of people of different characteristics.

Your participation in this study is completely voluntary and you may withdraw at any time without consequence. There are no anticipated risks to this study. You are eligible to participate if you are a benefit-eligible employee of Weber State University. If you have any questions or concerns about our study, please feel free to contact one of us at the numbers listed below. This research has been approved by both Utah State and Weber State's Institutional Review Board for the protection of human subjects. If you have any questions about your rights as a participant, you may call True Rubal at (435) 797-1821.

Please retain a copy of this informed consent for your own record and reply back a signed copy. We look forward to having you participate in our study!

\begin{tabular}{|c|c|}
\hline $\begin{array}{l}\text { Edward M. Heath, Ph.D. Date } \\
\text { Professor }\end{array}$ & $\begin{array}{l}\text { Trever Ball, B.S. } \\
\text { Researcher }\end{array}$ \\
\hline $\begin{array}{l}\text { Dept. of Health, Physical Education \& } \\
\text { Recreation }\end{array}$ & $\begin{array}{l}\text { Dept. of Health Promotion and Human } \\
\text { Performance }\end{array}$ \\
\hline $\begin{array}{l}\text { Utah State University } \\
\text { (435) } 797-3306\end{array}$ & $\begin{array}{l}\text { Weber State University } \\
(801) 626-7372\end{array}$ \\
\hline
\end{tabular}

Please sign (type full name) and date this document if you have read the above information and understand it. 
Appendix B. IRB Approval Letter 
Appendix C. Instrument 


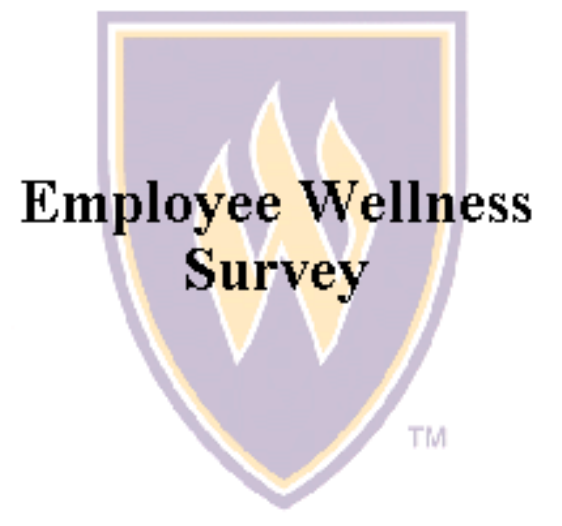

\section{Informed consent}

\section{Demographics}

Gender

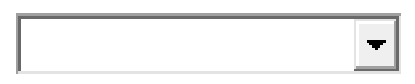

Age group

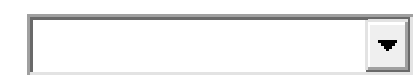

Education

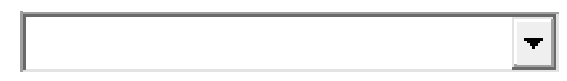

University Classification

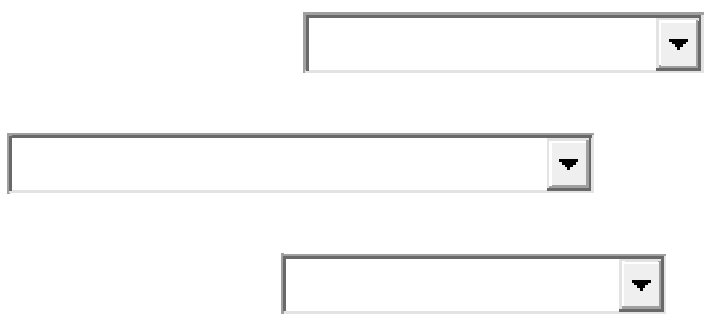

Physical Activity Level

Height in Inches (to nearest half inch)

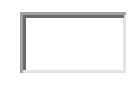

Weight (to nearest pound)

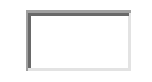

2. Please check all of the Weber State Employee Wellness services you have participated in during the past year:

$\Gamma \quad$ Health screening 


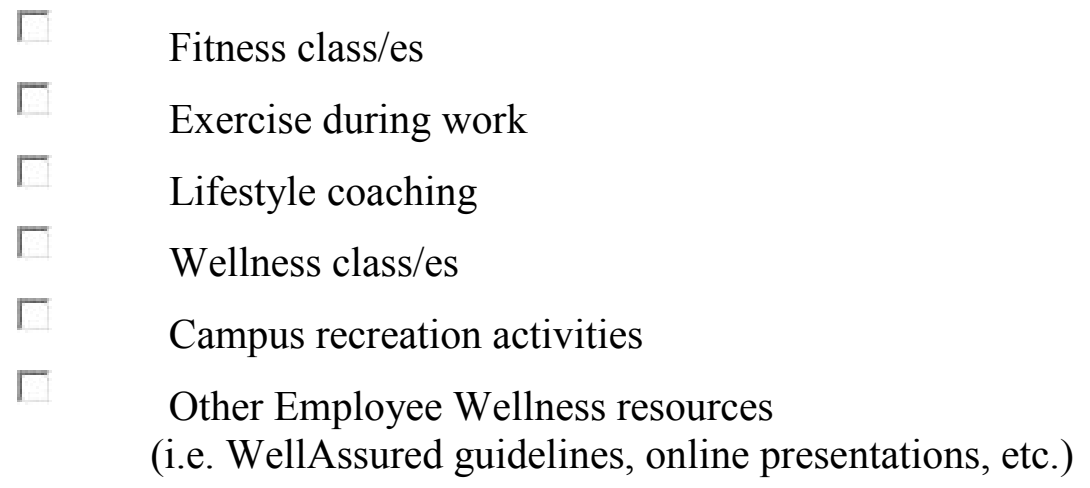

3. Please check each free health promotion service or policy you are likely to use (or currently use) at work? You may select any number of applicable services or policies. If you are not likely to use an item at work please indicate why.

a. Access to a fitness center. (max 35 characters)

b. On-site exercise classes.

c. Personalized diet or exercise counseling.

Г If not likely, why?

d. Sports leagues.

e. Health screening tests.

f. Paid time to exercise at work.

g. Confidential stress or depression screening and management.

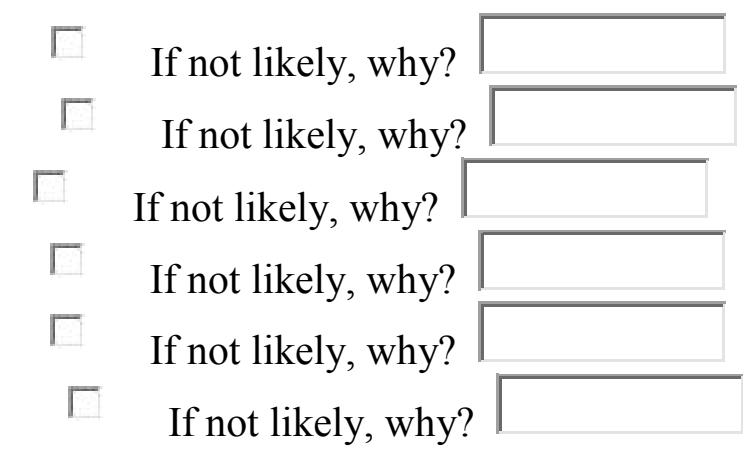

4. Please select each free wellness program elements you would be likely to use (or currently use) at work? You may select any number of applicable elements. If you are not likely to use an item at work please indicate why.

a. Online tools for tracking food and exercise.

Г If not likely, why?

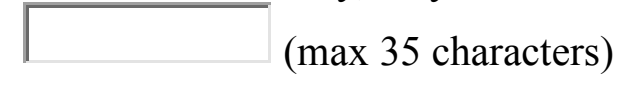

b. Healthy food choices in vending machines \& cafeterias. $\quad$ If not likely, why?

c. Healthy eating or healthy cooking classes.

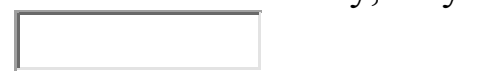

d. Weight loss program.

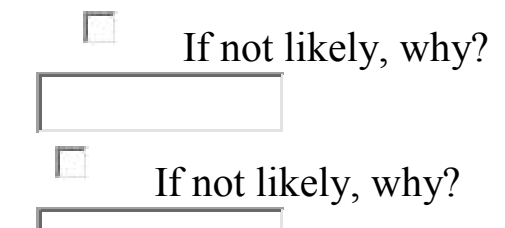


e. Weight loss support group.

If not likely, why?

f. Other (type in text box).

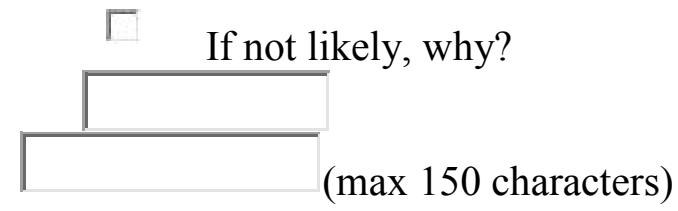

5. While considering your possible barriers to using the wellness services in questions $\# 1$ and \#2 which of the potential barriers below keep you from participating in a free wellness program here at work? You may select any number of applicable barriers.
a. Lack of energy
b. No interest.
c. No time during work day.
f. Lack of self-discipline.
g. Current injury or ill-health.
h. Support of supervisor.
f. Other (type in text box).

d. Already involved in other, similar programs or activities.

e. Would not want to participate in programs with other employees.

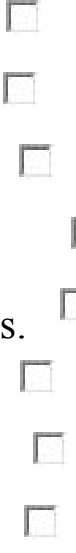

6. Which, if any, of these six elements would, or currently make you interested in participating in the free wellness program here at work? You may select any number of the applicable incentives.
a. Encouragement from supervisor.
b. Getting paid time off to attend.
c. Having programs held at a convenient time.
d. Having programs held at a convenient location.
e. Having good coworker participation.
f. Being able to invite family members or friends to come.

g. Other (type in text box).

If you have any other comments concerning your barriers or incentives to participation in the WSU employee wellness program, as well other interests please type them below. 


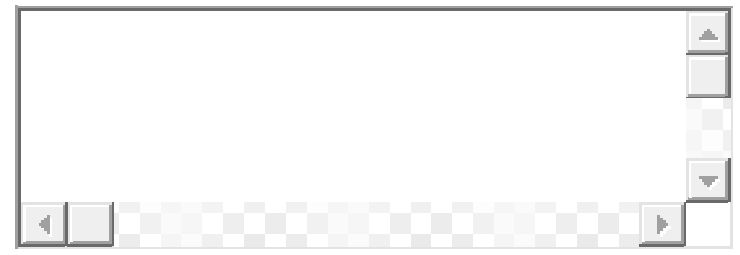

Please click "Submit" below when you are finished.

Thank-you for your participation!

Submit $\underline{\text { Reset }}$

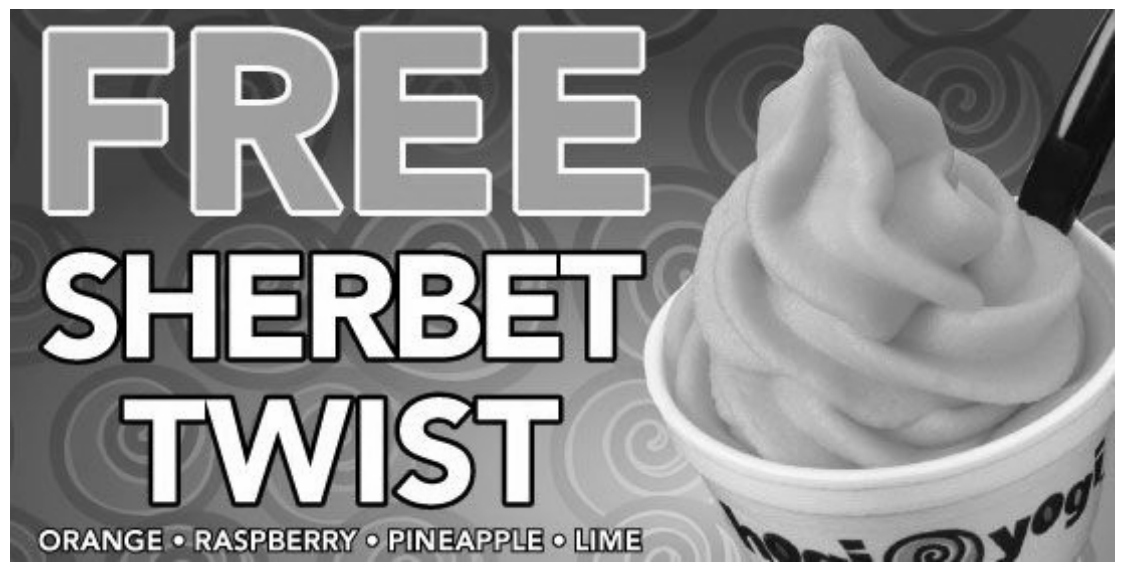

